\title{
SOOT MASS ESTIMATION FROM ELECTRICAL CAPACITANCE TOMOGRAPHY IMAGING FOR A DIESEL PARTICULATE FILTER
}

\author{
A Thesis \\ Submitted to the Faculty \\ of \\ Purdue University \\ by
}

Salah E. Hassan

\begin{abstract}
In Partial Fulfillment of the
Requirements for the Degree

of

Master of Science in Mechanical Engineering
\end{abstract}

May 2020

Purdue University

Indianapolis, Indiana 


\section{THE PURDUE UNIVERSITY GRADUATE SCHOOL STATEMENT OF THESIS APPROVAL}

Dr. Sohel Anwar, Chair

Department of Mechanical and Energy Engineering

Dr. Hazim El-Mounayri

Department of Mechanical and Energy Engineering

Dr. Andres Tovar

Department of Mechanical and Energy Engineering

Approved by:

Dr. Sohel Anwar

Chair of the Graduate Program 
This Thesis is dedicated to the memory of my parents, Karar and Shadia, to my beloved small family, my sister, Samira, my wife, Nosayba, my darling kids, Mohamed and Shadia. 


\section{ACKNOWLEDGMENTS}

I would like to express my sincere gratefulness to my advisor Dr. Sohel Anwar, for his continuous support throughout the course of my thesis and study, for his patience, motivation, knowledge.His guidance was a valuable key in my success of this project. Besides my advisor, I would like to thank the rest of my thesis committee. Dr.Hazim, and Dr. Tovar, for their deep, and insightful comments, and hard questions.

My sincere thanks also goes to my colleagues, Mohamed Khattab (Mechanical Engineering), Ammar Ali (Mechanical Engineering), Adish Krishna(Mechanical Engineering), Omar Siedahmed (Electrical Engineering). 
TABLE OF CONTENTS

Page

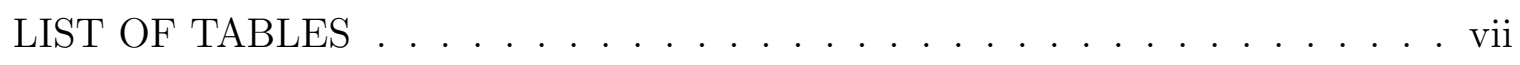

LIST OF FIGURES . . . . . . . . . . . . . . . . . . . viii

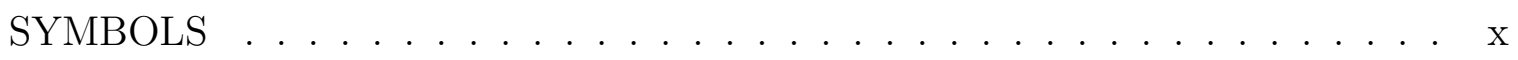

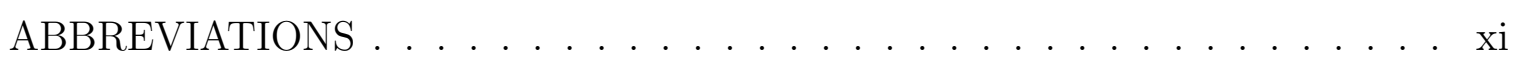

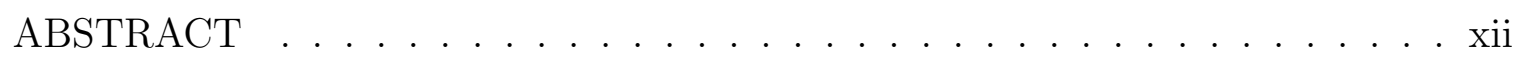

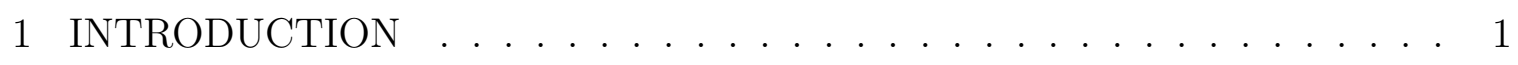

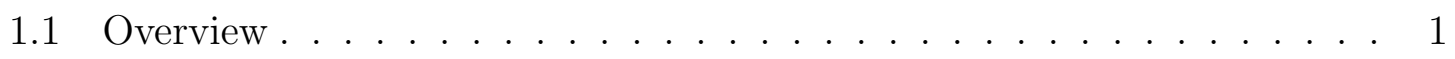

1.2 Problem Statement . . . . . . . . . . . . . . . . . . 3

1.3 Research Objective .................... 4

2 ELECTRICAL CAPACITANCE TOMOGRAPHY (ECT) - LITERATURE

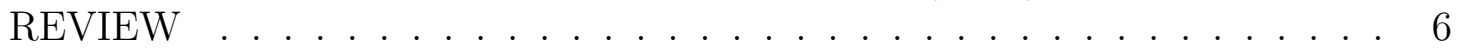

3 DESIGN OF AN ELECTRICAL CAPACITANCE TOMOGRAPHY SYSTEM 9

3.1 ECT Model Design . . . . . . . . . . . . . . . . . . 9

3.2 Image Reconstruction . . . . . . . . . . . . . . . . . . 10

3.2.1 Image Reconstruction using Linear Back Projection . . . . . . 11

3.2.2 Direct Techniques to Generate Sensitivity Matrix . . . . . . . . 12

3.2.3 Soot Load Estimation from Pixel Gray-Level Value . . . . . . . 12

4 SOOT MASS ESTIMATION FROM RECONSTRUCTED IMAGE . . . . 13 
4.1 Soot Mass Estimation _. . . . . . . . . . . . . . . 17

4.2 Computational Results and Discussion . . . . . . . . . . . . . 21

5 VALIDATION OF SOOT ESTIMATION USING FINITE ELEMENT ANAL-

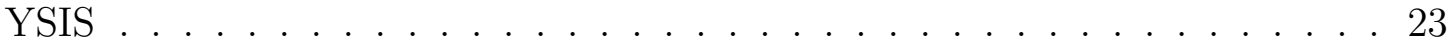

5.1 ANSYS Electronic Maxwell 3D Model . . . . . . . . . . . . . 23

5.2 Geometric Model . . . . . . . . . . . . . . . . 25

5.3 Material Selection . . . . . . . . . . . . . . . . 26

5.4 Electrodes Voltage and Solution Matrix . . . . . . . . . . . . . . 27

5.5 Voltage Distribution Simulation . . . . . . . . . . . . . . 28

5.6 Sensitivity Matrix . . . . . . . . . . . . . . . . 29

5.7 Capacitance Data Collection . . . . . . . . . . . . . 31

5.8 Circumferential Distributed Soot . . . . . . . . . . . . . . . 34

6 ANSYS'S IMAGES AND COMPUTATIONAL RESULTS . . . . . . . . . . 35

6.1 Soot Estimation Method using ANSYS Images . . . . . . . . . . . 35

6.2 Images (Gray-Level)- Circumferential Distributed Soot . . . . . . . . . 36

6.3 Ansys Validation and Results and Discussion . . . . . . . . . . . . 40

7 CONCLUSION AND FUTURE WORK . . . . . . . . . . . . . . 44

7.1 Conclusion . . . . . . . . . . . . . . . . . . 44

7.2 Future Work . . . . . . . . . . . . . . . . . 45

REFERENCES . . . . . . . . . . . . . . . . . . 47 


\section{LIST OF TABLES}

Table

4.1 Inter-Electrode's Voltage (V) measurements for different samples of soot mass (grams). . . . . . . . . . . . . . . . . . 14

4.2 Estimated weights using nonlinear polynomial equation. . . . . . . . . . . 20

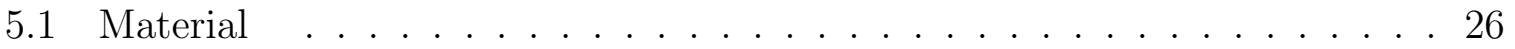

5.2 Maxwell solution matrix set-up . . . . . . . . . . . . . . . 28

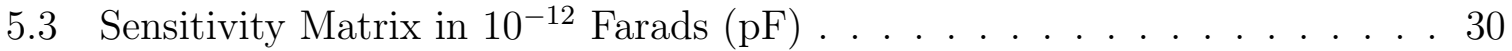

5.4 Random Filling Distribution in $10^{-12}$ Farads $(\mathrm{pF})$. . . . . . . . . . . . 32

5.5 Normalized Sensitivity Matrix . . . . . . . . . . . . . . 33

5.6 Circumferential Filling Distribution in $10^{-12}$ Farads $(\mathrm{pF}) \ldots . . . . . .34$

6.1 Nos. of filled holes vs Gray-Level Random Distribution . . . . . . . . . . . 38

6.2 Circumferential Distribution Estimated Weight . . . . . . . . . . . . . 39

6.3 Random vs Circumferential Distribution (Errors) . . . . . . . . . . . 40 


\section{LIST OF FIGURES}

Figure

Page

1.1 DPF (Diesel Particulate Filter) $[3] \ldots \ldots$. . . . . . . . . . . 2

1.2 Thermal Regeneration Operation $[4] \ldots \ldots \ldots$

3.1 ECT sensor diagram $[14] \ldots \ldots \ldots \ldots \ldots$

3.2 DPF Sensor Components . . . . . . . . . . . . . . . . . 10

4.1 ECT Image for a soot mass of 56.6 grams. . . . . . . . . . . . . . . 15

4.2 ECT Image for a soot mass of 172.2 grams. . . . . . . . . . . . . . . 15

4.3 ECT Image for a soot mass of 112.6 grams. . . . . . . . . . . . . . . . 16

4.4 Estimated Weight Polynomial Curve . . . . . . . . . . . . . . 18

4.5 Actual soot mass vs Estimated soot mass. . . . . . . . . . . . . . . 21

4.6 Soot mass estimation accuracy . . . . . . . . . . . . . . . 22

5.1 Four Conductors' Mutual Capacitance [16] . . . . . . . . . . . . . . 24

5.2 Diesel Particulate Filter $(\mathrm{DPF}) \ldots \ldots . \ldots . \ldots . \ldots . \ldots$

5.3 Pixels and Holes Distribution . . . . . . . . . . . . . . 26

5.4 Voltage of 5 Volts applied to Electrode $1 \ldots \ldots$. . . . . . . . . 27

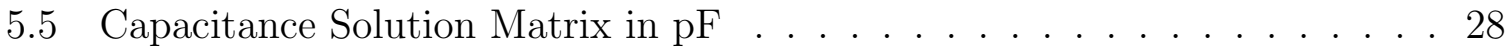

5.6 Voltage Distribution . . . . . . . . . . . . . . . . 29

6.1 Randomly Distributed and filled holes. . . . . . . . . . . . . . . . 35 
Figure

6.2 Randomly Distributed Soot . . . . . . . . . . . . . 37

6.3 Circumferential Distributed Soot . . . . . . . . . . . . . . 37

6.4 Random Distribution Error $\%$. . . . . . . . . . . . . . . . 41

6.5 Circumferential Distribution -Actual Nos of holes filled vs Estimated . . . 42

6.6 Random vs Circumferential Distribution . . . . . . . . . . . . . . . . . 42

6.7 Random vs Circumferential Distribution Errors . . . . . . . . . . . . . 43

7.1 Voltage fill-in data vs Gray-Level (Experimental), and Capacitance fill-in data vs Gray-Level (validation) . . . . . . . . . . . . . . . . 45 


\section{SYMBOLS}

$\begin{array}{cl}A & \text { Electrode Surface Area } \\ {[K]} & \text { Normalized pixel permittivity } \\ M & \text { Number of capacitance measurements } \\ N & \text { Number of electrodes } \\ i & \text { Source electrode } \\ J & \text { Receiving electrode } \\ C & \text { Capacitance value } \\ C i j & \text { Capacitance between electrodes i and j } \\ C i(e m p) & \text { Capacitance measurement, when Sensor empty } \\ C i(f u l) & \text { Capacitance measurement, when Sensor fully filled } \\ E & \text { Electric field strength between the plates } \\ \varepsilon & \text { Dielectric permittivity } \\ \varepsilon_{r} & \text { Relative Dielectric permittivity } \\ \varepsilon_{0} & \text { Vacuum Dielectric permittivity } \\ {[S]} & \text { Sensitivity distribution matrix } \\ S^{T} & \text { Transpose of sensitivity distribution } \\ S^{-1} & \text { Inverse of sensitivity distribution } \\ Q & \text { Electrical Charge } \\ V & \text { Voltage } \\ D, d & \text { Diameter (m) } \\ m & \text { Mass } \\ v & \text { Velocity } \\ \Delta P & \text { Differential pressure }\end{array}$




\title{
ABBREVIATIONS
}

\author{
ATS After Treatment Systems \\ DOC Diesel Oxidation Catalyst \\ DPF Diesel Particulate Filter \\ ECT Electrical Capacitance Tomograph \\ EPA Environmental Protection Agency \\ LBP Linear Back Projection \\ PM Particulate Matter \\ SCR Selective Catalytic Reduction
}




\begin{abstract}
Hassan, Salah E., M. S. M. E., Purdue University, May 2020. Soot Mass Estimation from Electrical Capacitance Tomography Imaging for a Diesel Particulate Filter. Major Professor: Sohel Anwar.
\end{abstract}

The Electrical capacitance tomography (ECT) method has recently been adapted to obtain tomographic images of the cross section of a diesel particulate filter (DPF). However, a soot mass estimation algorithm is still needed to translate the ECT image pixel data to obtain soot load in the DPF. In this research, we propose an estimation method to quantify the soot load in a DPF through an inverse algorithm that uses the ECT images commonly generated by a back-projection algorithm. The grayscale pixel data generated from ECT is used in a matrix equation to estimate the permittivity distribution of the cross section of the DPF. Since these permittivity data has direct correlation with the soot mass present inside the DPF, a permittivity to soot mass distribution relationship is established first. A numerical estimation algorithm is then developed to compute the soot mass accounting for the mass distribution across the cross-section of the DPF as well as the dimension of the DPF along the exhaust flow direction. Firstly, ANSYS Electronic Desktop software is used to compute the capacitance matrix for different amounts of soot filled in the DPF, furthermore it also analyzed different soot distribution types applied to the DPF. The Analysis helped in constructing the sensitivity matrix which was used in the numerical estimation algorithm. Experimental data have been further used to verify the proposed soot estimation algorithm which compares the estimated values with the actual measured soot mass to validate the performance of the proposed algorithm. 


\section{INTRODUCTION}

\subsection{Overview}

One of the challenging issues with diesel engines is its harmful emission to the environment. It has been estimated that emission from diesel engines accounts for two-thirds of all particulate matter (PM) emitted from the US transportation sources and have been reported to be significantly more harmful than those from gasoline vehicles. Moreover diesel engines are responsible for the release of harmful gasses such as $\mathrm{HC}, \mathrm{CO}, \mathrm{NOx}$ and particulate matter into the atmosphere. These emissions affect human respiratory system beside its hazardous effects on environment.

Particulate matter or soot is created during the incomplete combustion of diesel fuel, which contributes to the problem by releasing particulates directly into the air and by emitting nitrogen oxides and sulfur oxides, which transform into secondary particulates in the atmosphere [1]. As emission regulations become more stringent, diesel engines must be equipped with after-treatment systems to meet emission re-

quirements [1], [2], and according to U.S. Environmental Protection Agency (EPA ), diesel engine manufacturers are required to meet these regulations .

Modern Diesel Engines have been using a diesel particulate filter (DPF) as shown in figure [1.1] since the early of 1980s to capture carbon particles with efficiency level of more than $90 \%$. With this type of after-treatment emission elimination, DPF retains exhaust gas particles by forcing the gas to flow through the filter. The accumulation of PM is harmful for the engine as it increases the back pressure on the engine's exhaust manifold, exerts more loads on pistons, and produces more emission than initially has which leads to the decline of engine efficiency .Consequently, it elevates the temperature, or it creates a temperature bank on the exhaust upstream, 
leading to DPF body cracks and it might cause a damage to other after-treatment components, as well as the back pressure and high temperature caused by active regeneration process. These conditions constitute main factor of NOx gas production One traditional solution for the soot accumulation inside the DPF and its conse-

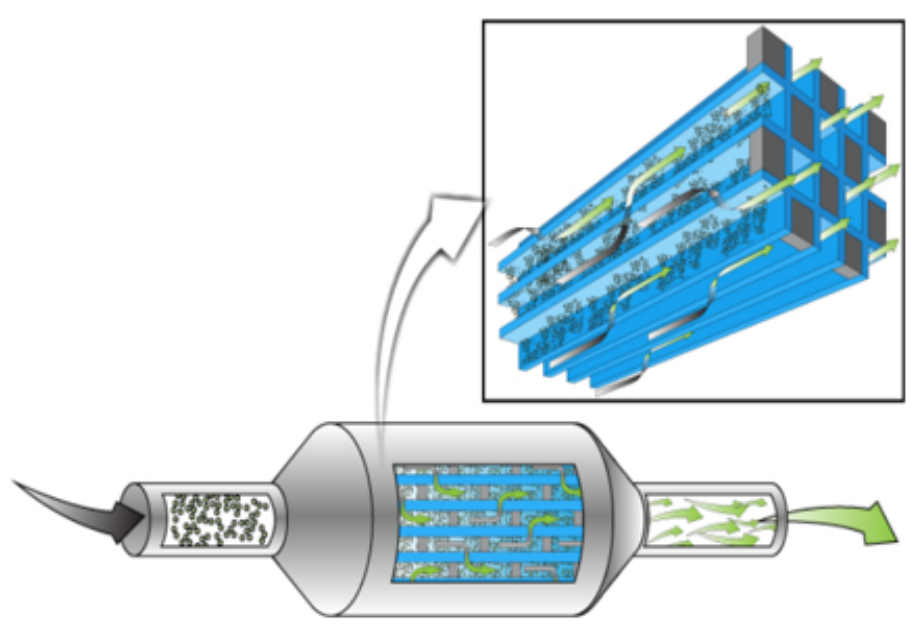

Figure 1.1.: DPF (Diesel Particulate Filter) [3]

quences on the diesel engine performance is the active thermal regeneration process which burns the DPF's accumulated soot using extra fuel injected directly into the filter intermittently in order to provide a way of removing particulates from the DPF to restore its function effectively. This cycle of operation can be performed either continuously (passive regeneration), or periodically (active regeneration), when the soot trapped inside the DPF. In both cases, when the on-board pre-determined control parameters met, a cycle of regeneration is performed without operator intervention. Thermal regeneration of diesel particulate filters is typically employed, where the collected particulates are oxidized by oxygen and/or nitrogen dioxide to gaseous products, primarily to carbon dioxide. Thermal regeneration, schematically represented in Figure 1-2, consider by far the cleanest and most attractive method of operating diesel particulate filters [4]. 


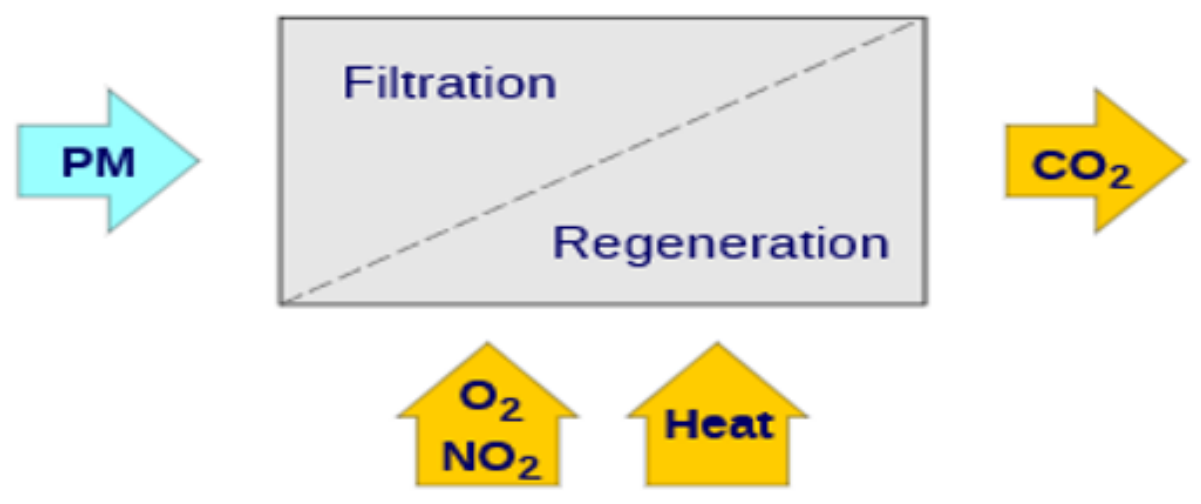

Figure 1.2.: Thermal Regeneration Operation [4]

\subsection{Problem Statement}

Diesel Particulate Filters (DPF) are used in the after-treatment (ATS) configuration for a diesel engine, to primarily capture soot and Particulate Matter (PM). As fuel burns, the DPF collects and stores up to $98 \%$ of incombustible particles in the form of ash and soot, which negatively impacts the operation of DPF, and diesel engine efficiency as well. Moreover, the Environmental Protection Agency (EPA) is gearing up to significantly tighten air-pollution regulations and standards , as diesel engine manufacturers have to reduce emissions of air pollutants, and to improve DPF soot estimation process in particular, in order, to comply with these standards.

Currently, the most used technology to measure soot is differential pressure ( $\Delta \mathrm{P})$ sensor. For $(\Delta \mathrm{P})$ sensor, however, it should be emphasized that the pressure drop signal is not a direct measurement of the soot mass in the filter, and secondly this method is known to have relatively poor accuracy of soot estimation ( $50 \%$ from the true soot load ) [3], specifically at a lower exhaust volumetric flow. Besides, the nature of pulsating airflow of engine exhaust gas, which leads to a significant deviation in determining the soot load.

Soot mass estimation inaccuracy has a direct effect on the efficiency of the regeneration process to purge the restrictive soot out,which eventually increases fuel 
consumption. As a result, fuel dosing for active regeneration may not be optimal. Since, it has been shown that fuel penalty caused by regeneration $(2.2 \%$ to $5.3 \%)$ is more than fuel penalty due to back-pressure $(1.5 \%$ to $2.0 \%)$ [1]. Other impacts of inaccurate estimation of differential pressure method is creation of higher temperature bank on exhaust downstream and after treatment system components, leading to DPF body rupture and other after-treatment system components such as diesel oxidation catalyst (DOC), and Selective Catalytic Reduction (SCR).

Accuracy of soot load estimation plays a critical role in determining the optimal conditions of DPF regenerative fuel injection, and increases DPF life span. In addition, the increasingly stringent environmental regulations for diesel engine emissions are driving efforts to develop concepts for estimating DPF soot load emissions.

In this research, a method of soot load estimation is developed using electrical capacitance tomography imaging to improve the accuracy of soot estimation.

\subsection{Research Objective}

The main objective of this research is to develop a soot estimation methodology using ECT image.

In this project, ECT image pixel values (gray-level) have been used as foundation to develop an estimation approach. This approach depends on, ECT imaging reconstruction techniques, along with an estimation algorithm. This Research has the following specific objectives:

1- To estimate soot load in diesel engine particulate matter (DPF) using electrical capacitance tomography imaging by :

a - Studying Sensitivity Matrix formation methods ,for ECT image generation.

$\mathrm{b}$ - Researching different image reconstruction techniques for ECT, in order to develop soot estimation algorithm.

2- Develop a finite element analysis (FEA) model to validate experimental results and perform the following: 
a - Investigate the relationship between capacitance, voltage, and DPF soot load from experimental and validation data.

b - Develop different soot deposition patterns to analyze and evaluate their effects on gray-level values/ soot estimation . 


\section{ELECTRICAL CAPACITANCE TOMOGRAPHY (ECT) - LITERATURE REVIEW}

Electrical capacitance tomography (ECT) has been developed and used since late 1980s for visualization and measurement of a permittivity distribution in a cross section of a pipe carrying fluid using a multi-electrode capacitance sensor [5]. As one of the electrical process tomography imaging technologies, Electrical Capacitance Tomography (ECT) is featured upon its advantages over other tomography methods for lower costs, no-irradiative, and non-invasive methods.Despite, its appealing advantages, ECT has some major challenges and drawbacks such as processing a low resolution images, since the ECT system is limited to few measurements per one measurement cycle, making the image reconstruction problem ill-posed, and under determined [6].

In the past several years, there have been a lot of focus on addressing the issue of the measurement of accumulated particular matter inside the DPF. One effective approach is the Electrical Capacitance Tomography using a multi-electrode capacitance sensor to estimate the soot load. This method utilizes the measurement of the soot load permittivity distribution across-section of DPF using a multi-electrode capacitance sensor. The aim of ECT is to calculate and visualize the unknown permittivity distribution via measuring capacitances between pairs of peripheral electrodes around samples. The samples under test of ECT are normally dielectric or negligibly conductive, since the conductivity affect's the measuring of ECT and leads to the failure of imaging [7].

ECT sensor is widely used in process control for monitoring and control the quality of an industrial process. It is used as one of non-destructive testing methods with potential applications in the measurement of flow of fluids in pipes [8]. It has 
been adopted in the industry in wide range of applications such as fluid flow monitoring and other industrial applications, utilizing the basic principles of electrical capacitance tomography (ECT) of taking multiple measurements at the periphery of required part of process to be monitored, or pipeline and combining these measured data to provide a visualized information of the this process using its electrical properties ,however there are some challenges and limitation regarding ECT such as its low accuracy and inadequate spatial resolution of its reconstructed images as compared to other methods that are commonly used in image reconstruction [9]. On other hand, capacitive sensors are very convenient because they only consist of electrodes and are sensitive to the electrical properties of materials and their distribution. Moreover, they can work at low frequencies with low power consumption [12]. As a result, it has been observed in industry an increased interest in electrical tomography techniques due to their capabilities in the process control and other applications, inspired by their relatively low cost, speed, and safety. Nevertheless, the relatively poor reconstructed images, beside their nonlinearity, and the ill pawedness of system equation [10], [11], [12], [13].

In this research, a novel approach to estimate DPF's soot load based on its ECT reconstructed image's (pixel) gray-level value is presented, utilizes the numerical sum of the gray level value, as it assumed to be a good indicator for spatial soot load. This research is an attempt to continue on in previous research of (Development of a novel sensor for soot deposition measurement in a diesel particulate filter using electrical capacitance tomography) done by Ragibul Huq [2014], the research focused on generating digital image, reflecting deposited spatial soot load. On the other hand this research focus on estimating soot mass from generated digital image as reverse process of previous project, considering the proportional relationship between the dielectric soot load filled inside the DPF and the permittivity values calculated using the measured inter-electrode's electrical capacitance.This method utilizes sensitivity matrix as tool to transform soot load distribution (dielectric) into a pixel domain, while the numerical sum of pixel value as a gauging tool to estimate accumulated 
soot in DPF, from experimental data. This approach assumes voltage measurement as measure of inter-electrodes capacitance, while on the other hand, validation process used capacitance data as fill-in of inter-electrode's measurement as it will be shown in Ansys Electronic Desktop analysis in chapter 5. 


\section{DESIGN OF AN ELECTRICAL CAPACITANCE TOMOGRAPHY SYSTEM}

\subsection{ECT Model Design}

A basic ECT system normally consists of a capacitance sensor, a measurement unit of capacitance and a computer system for image reconstruction process as shown in figure 3.1. The sensor hardware in ECT is typically composed of a number of $\mathrm{n}$ electrodes surrounding the wall of the process vessel as illustrated in figure 3.1. The number of independent capacitance measurement available in a such a configuration is $\mathrm{n}(\mathrm{n}-1) / 2$.

Where $\mathrm{n}$ is the number of electrodes around the required imaging region.

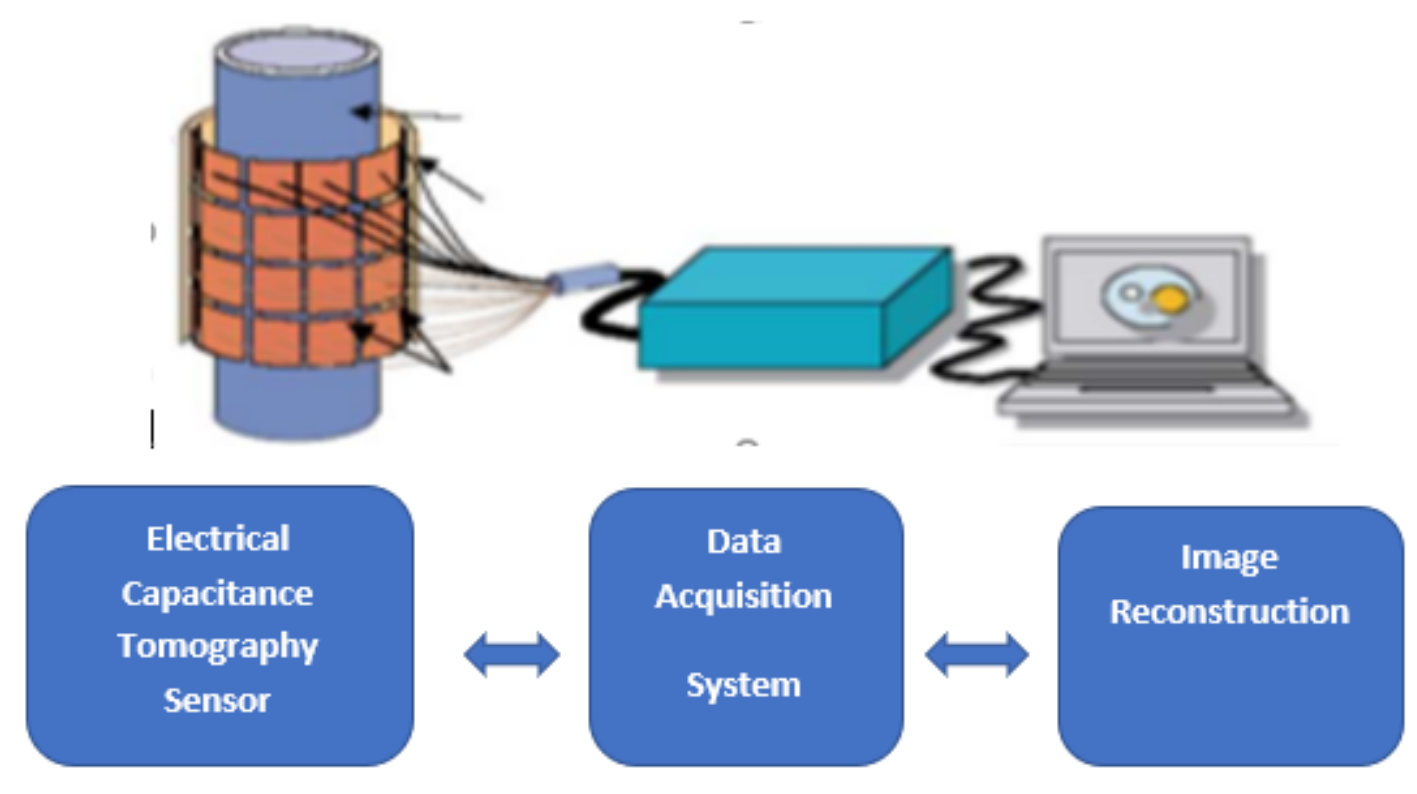

Figure 3.1.: ECT sensor diagram [14] 
The sensor is made up of $n$ electrodes mounted on the perimeter of the imaging area [13]. All independent mutual capacitance measurements are measured between sender electrodes connected to the source signal, and the other receiver electrodes where connected to the ground. Figure 3.2 shows an ECT sensor with n numbers of electrodes.

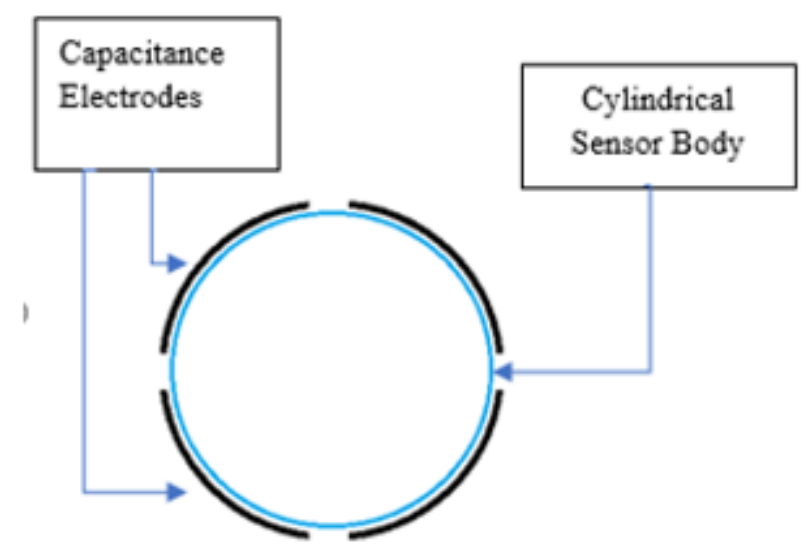

Figure 3.2.: DPF Sensor Components

The capacitance between two pairs of electrodes, i.e. a source electrode and a detector electrode, is obtained through equation (3.1).

$$
Q_{i}=c_{i j} \cdot V_{j}
$$

Qi is the charge quantity on electrode $\mathrm{i}$.

$\mathrm{c}_{i j}$ represents mutual capacitance between electrodes $i$ and $j$, $\mathrm{V}_{j} \quad$ is the voltage applied to electrode $j$.

\subsection{Image Reconstruction}

Soot estimation process relies on DPF reconstructed image which mainly means gray-level value, since Electrical Capacitance Tomography (ECT) system's main function is to image cross-sections of objects containing dielectric material, 
which in turn enables ECT to determine the material distribution over the crosssection using its permittivity distribution [14].

\subsubsection{Image Reconstruction using Linear Back Projection}

Linear back projection (LBP) was used to process ECT image reconstruction. In LBP, a multidimensional inverse problem needs to be solved. It has the advantage of dynamic and flexible process with good capability of image reconstruction, and it can be expressed as a function of sensitivity matrix as in equation (3.2) [15]:

$$
[C]=[S] \cdot[K]
$$

$[\mathrm{C}]=($ Mc x 1) normalized electrode matrix.

To determine the permittivity distribution matrix from the measured capacitance vector, a solution for equation (3.2) should be obtained. Let us consider a reconstructed square grid image of N pixels, generated by Linear Back Projection (LBP) algorithm, with known permittivity distribution matrix $[\mathrm{S}]$. The inverse transform Q can be obtained as shown in (3.3). An approximation of LBP method uses the transpose of [3.4] in (3.2), to have a pseudo-inverse matrix of the dimensions ( $\mathrm{N} \mathrm{x} \mathrm{M})$ that can be used in (3.4) where $[S]^{T}$ assumed to be equal to $[\mathrm{Q}]$.

$$
\begin{aligned}
& {[K]=[Q] \cdot[C]} \\
& {[K]=[S]^{T} \cdot[C]}
\end{aligned}
$$

$[\mathrm{C}]=\mathrm{M} \times 1$ Vector containing the normalized electrode-pair capacitances (in the nominal range 0 to 1 ).

$\mathrm{K}=\mathrm{N} \times 1$ Vector containing normalized pixel permittivity's (in the nominal range 0 to 1$)$.

$\mathrm{N}$ is the number of pixels representing the sensor cross-section [1]

$\mathrm{S}=\mathrm{M} \times \mathrm{N}$ matrix containing set of sensitivity matrices for each electrode-pair. 


\subsubsection{Direct Techniques to Generate Sensitivity Matrix}

Direct technique is used to generate sensitivity matrix model by measuring the response of capacitance for permittivity perturbations. The basic idea relies on the assumption that the sensitivity is independent of permittivity distribution. The matrix is formed by measuring the capacitances for each pair of electrodes and constructing array of independent combination of electrodes measurement of high electrical permittivity in the imaging area of interest. Using high and low permittivity material, measurements can be normalized accordingly, as shown in equation (3.5) [13]:

$$
S_{i}(N)=\left(C_{i}(N)-C_{i}(e m p)\right) /\left(C_{i}(f u l l)-C_{i}(e m p)\right)
$$

where $S_{i}(\mathrm{~N})$ is the sensitivity matrix element $[\mathrm{S}]$,

$C_{i}(\mathrm{~N})$ is the measured capacitance,

$C_{i}$ (emp) capacitance measurement when the sensor is filled with low permittivity, $C_{i}$ (full) capacitance measurement when the sensor is filled with high permittivity.

\subsubsection{Soot Load Estimation from Pixel Gray-Level Value}

Once normalized capacitance victor is obtained [C], linear back projection (LBP) algorithm equation (3.4) used to multiply [C] by the transpose of the sensitivity matrix $[\mathrm{S}]$ to produce pixel gray-level, vector[K], or the digital image for all given experimental deposited soot load samples. The numerical sum of gray-level value, $\sum$ $[\mathrm{K}]$ represents the value of pixel's gray-level generated from LBP algorithm, which is found to be well correlated with actual soot load weight. 


\section{SOOT MASS ESTIMATION FROM RECONSTRUCTED IMAGE}

As the sensitivity matrix forms a basis set from which image vectors can be obtained. Basically, each row of [S] represents the response of the sensor system to a small individual permittivity pixel in a uniform background [16] using direct techniques equation (3.5) and having normalized voltage data in table 4.1 using equation (3.5), as well as sensitivity matrix which has been built as shown below :

$S=\left[\begin{array}{lllllll}0.000 & 0.000 & 0.000 & 0.000 & 0.000 & 0.000 \\ 0.018 & 0.039 & 0.058 & 0.045 & 0.040 & 0.044 \\ 0.037 & 0.078 & 0.116 & 0.089 & 0.079 & 0.087 \\ 0.203 & 0.254 & 0.237 & 0.134 & 0.101 & 0.114 \\ 0.257 & 0.321 & 0.251 & 0.265 & 0.210 & 0.197 \\ 0.257 & 0.308 & 0.388 & 0.307 & 0.355 & 0.409 \\ 0.290 & 0.326 & 0.419 & 0.414 & 0.521 & 0.452 \\ 0.322 & 0.343 & 0.450 & 0.520 & 0.686 & 0.495 \\ 0.487 & 0.376 & 0.475 & 0.611 & 0.714 & 0.541 \\ 0.651 & 0.409 & 0.500 & 0.703 & 0.742 & 0.587 \\ 0.946 & 0.579 & 0.542 & 0.750 & 0.752 & 0.600 \\ 0.953 & 0.605 & 0.545 & 0.753 & 0.754 & 0.613 \\ 0.963 & 0.620 & 0.559 & 0.770 & 0.759 & 0.614 \\ 0.980 & 0.681 & 0.608 & 0.832 & 0.813 & 0.687 \\ 1.000 & 1.000 & 1.000 & 1.000 & 1.000 & 1.000\end{array}\right]$


Table 4.1.: Inter-Electrode's Voltage (V) measurements for different samples of soot mass (grams).

\begin{tabular}{|c|c|c|c|c|c|c|}
\hline Weight-Grams & A-B & A-C & A-D & B-C & B-D & C-D \\
\hline 0 & 3.63 & 3.71 & 3.68 & 3.75 & 3.79 & 3.68 \\
9.35 & 3.60 & 3.67 & 3.61 & 3.70 & 3.74 & 3.64 \\
18.7 & 3.58 & 3.62 & 3.54 & 3.64 & 3.69 & 3.59 \\
37.4 & 3.34 & 3.43 & 3.38 & 3.59 & 3.66 & 3.57 \\
56.3 & 3.27 & 3.35 & 3.37 & 3.43 & 3.53 & 3.49 \\
65.8 & 3.27 & 3.36 & 3.28 & 3.40 & 3.44 & 3.38 \\
84.8 & 3.27 & 3.37 & 3.19 & 3.37 & 3.35 & 3.28 \\
94.2 & 3.22 & 3.35 & 3.15 & 3.24 & 3.14 & 3.24 \\
112 & 3.17 & 3.33 & 3.11 & 3.11 & 2.93 & 3.19 \\
132 & 2.94 & 3.29 & 3.08 & 3.00 & 2.90 & 3.15 \\
151 & 2.71 & 3.25 & 3.05 & 2.88 & 2.86 & 3.10 \\
172 & 2.30 & 3.07 & 3.00 & 2.82 & 2.85 & 3.09 \\
192 & 2.29 & 3.04 & 2.99 & 2.82 & 2.85 & 3.08 \\
210 & 2.27 & 3.02 & 2.98 & 2.80 & 2.84 & 3.08 \\
220 & 2.25 & 2.95 & 2.91 & 2.72 & 2.78 & 3.01 \\
232 & 2.22 & 2.60 & 2.42 & 2.51 & 2.54 & 2.70 \\
FULL & 2.22 & 2.60 & 2.42 & 2.51 & 2.54 & 2.70 \\
EMPTY & 3.63 & 3.71 & 3.68 & 3.75 & 3.79 & 3.68 \\
\hline
\end{tabular}

After normalized capacitances [C] are obtained, MATLAB software was used to generate pixel gray-level matrix $[\mathrm{K}]$ (ECT image) for all given experimental soot load measurements. Figures 4.1, 4.2, and 4.3 show the ECT images for soot masses of 56.6, , 172.2 and 112.6 grams respectively. 


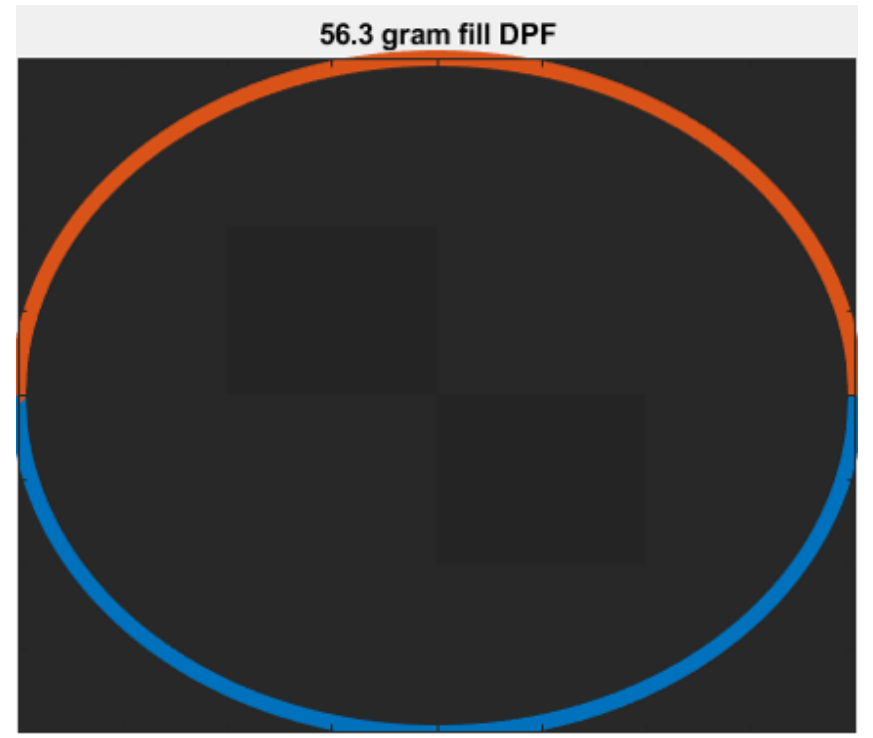

Figure 4.1.: ECT Image for a soot mass of 56.6 grams.

172.2 gram fill DPF

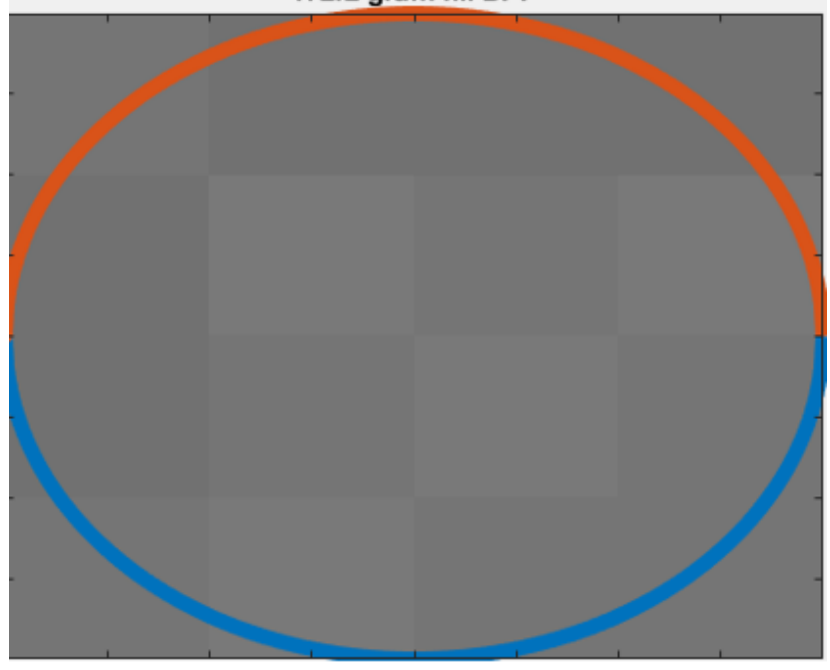

Figure 4.2.: ECT Image for a soot mass of 172.2 grams. 
112.6 gram fill DPF

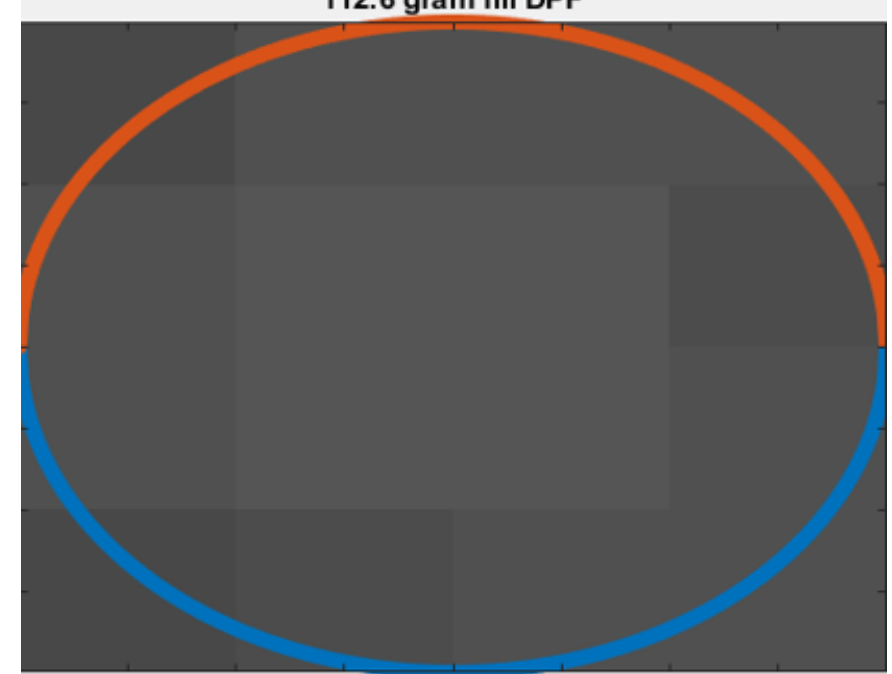

Figure 4.3.: ECT Image for a soot mass of 112.6 grams. 


\subsection{Soot Mass Estimation}

From the capacitance measurements obtained from inter-electrode data, as shown in table 4.1. It has been observed from the experimental data that, change in material deposited in sensor results in variations in the sensor measured voltage, an inversely proportional relationship formed as a result, between material deposited inside the DPF and voltage readings. This indicates that the more soot weight deposited, the more voltage reduction developed. In linear back projection method, it was explained in section 3.2.1, that in equation (3.4), the direct contributions of pixels (gray-level) $[\mathrm{K}]$ are the product of $\mathrm{S}$ and $\mathrm{C}$ matrices.

Digital image's pixel data which represented in gray-level value $[\mathrm{K}]$, arranged in numerical sum, it was explained in sample 172.2 grams later on this section. Table 4.2 shows that in the second column the sum of gray-level value, a proportional relationship clearly seen, as well, these results are plotted as shown in figure 4.4. A polynomial curve of the $6^{\text {th }}$ degree was fitted between soot mass weight and summation of gray level value as follows :

$$
y=a_{1} x^{6}+a_{2} x^{5}+a_{3} x^{4}+a_{4} x^{3}+a_{5} x^{2}+a_{6} x+a
$$

Where $\mathrm{y}$ represents estimated soot mass weight, $\mathrm{x}$ is the gray level value. Using curve fitting tools in excel $a_{1}, a_{2}, a_{3}, a_{4}, a_{5}$, and $a_{6}$ can be located respectively as below:

$$
\begin{aligned}
\mathrm{a}_{1}= & -1.05 E-13, \quad a_{2}=1.68761 E-10, \quad a_{3}=-9.85783 E-08 \\
& \mathrm{a}_{4}=2.5877 E-05, \quad a_{5}=-0.002829359, \quad a_{6}=0.401355946 \\
\mathrm{a}= & 0
\end{aligned}
$$




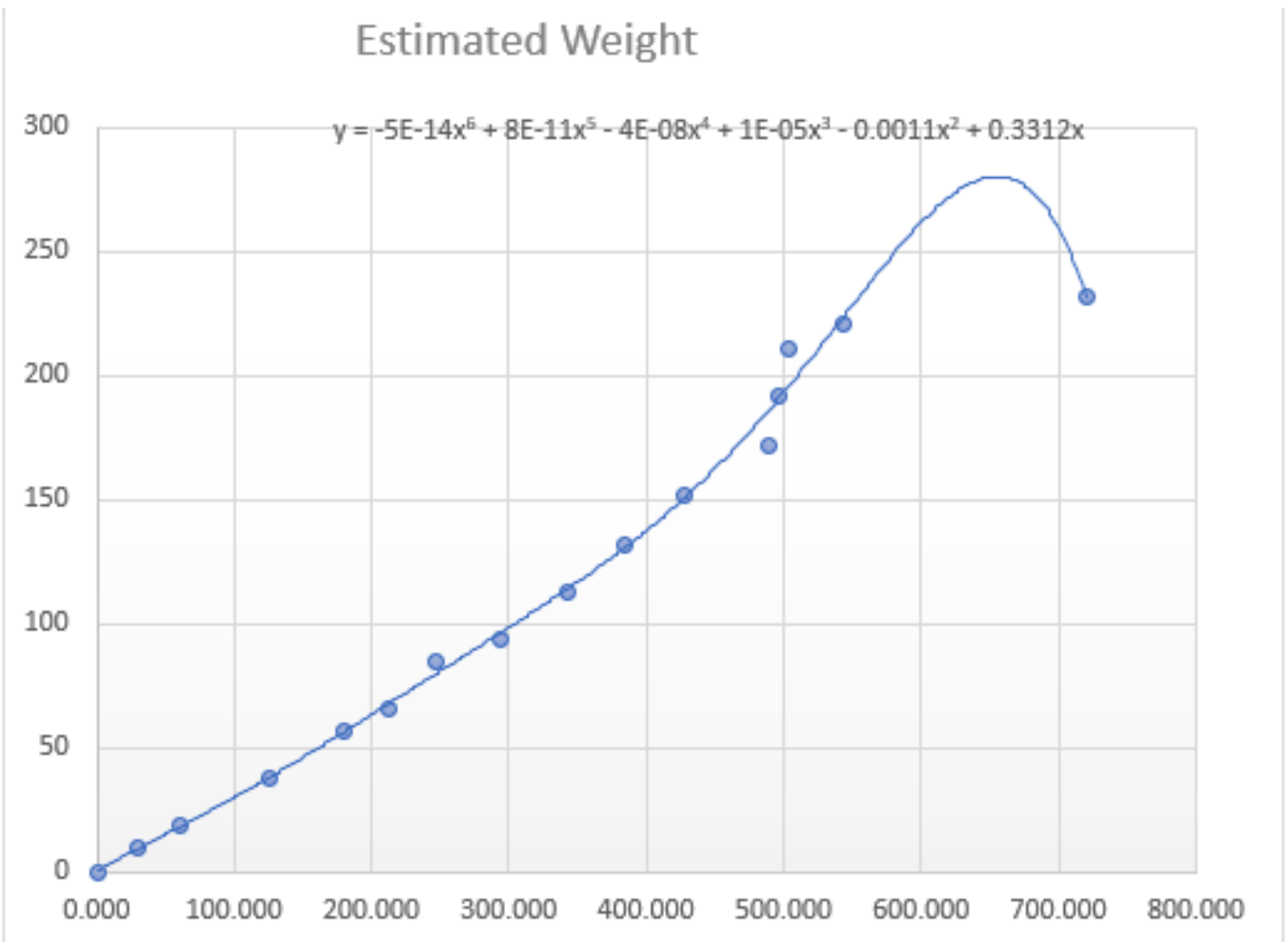

Figure 4.4.: Estimated Weight Polynomial Curve

$$
y=-(5 E-14) x^{6}+(8 E-11) x^{5}-(4 E-08) x^{4}+(1 E-05) x^{3}-0.0011 x^{2}+0.3312 x .
$$

An estimated weight y can be obtained from the polynomial equation by substituting gray-level value $\mathrm{x}$ at equation right hand as shown in table 4.2. This direct relationship between gray-level value $[\mathrm{K}]$ and actual weight $[\mathrm{WA}]$ deposited inside the DPF can be computed from equation (3.4) in section 3.2.1, where $C \alpha \sum K$.

This is based on this proportional relationship between measured voltage, and corresponded gray-level value of generated pixel. An example calculation can be done to estimate soot mass deposited into the DPF is shown below.

$$
\left[\mathrm{K}_{172.2}\right]=[S]^{T} \cdot\left[C_{172.2}\right]
$$


Where $\quad\left[K_{172.2}\right]$ is gray -level value of 172.2 -gram pixel matrix.

$[S]^{T}$ is transpose of Sensitivity Matrix .

$\left[C_{172.2}\right]$ is normalized 172.2 -gram victor.

$$
y=-(5 E-14) x^{6}+(8 E-11) x^{5}-(4 E-08) x^{4}+(1 E-05) x^{3}-0.0011 x^{2}+0.3312 x .
$$

$$
\begin{aligned}
{\left[\mathrm{K}_{172.2}\right]=} & {\left[\begin{array}{llll}
30.73 & 29.75 & 29.75 & 29.75 \\
29.75 & 31.16 & 30.90 & 31.17 \\
29.75 & 30.90 & 31.68 & 30.82 \\
30.73 & 31.17 & 30.82 & 30.55
\end{array}\right] } \\
& \sum\left[K_{172.2}\right]=489.369
\end{aligned}
$$

The gray-level of pixel 172.2 gram is multiplied by coefficient of 45 and applied to all other weight samples, in order to obtain more contrast in gray scale level which eventually will have no effect in the polynomial curve plot.

By substituting $\sum\left[K_{172.2}\right]$ for $\mathrm{x}$ in equation (4.2). The Estimated weight is assumed a $\mathrm{y}=186.35$ gram.

The difference between actual and estimated weight (Error) is given by:

$$
\begin{gathered}
\text { Error }=(\mathrm{WE}-\mathrm{WA}) / \mathrm{WA} \\
=(186.35-172.2) / 172.2=8.22 \%
\end{gathered}
$$

Using equation (4.2) to calculate all other weight samples as shown in table (4.2) as follows: 
Table 4.2.: Estimated weights using nonlinear polynomial equation.

\begin{tabular}{|c|c|c|c|}
\hline Actual Weight & Gray-Level Value & Estimated Soot Mass & Error1 \% \\
\hline 0.00 & 0.000 & 0.00 & 0.00 \\
9.35 & 30.241 & 9.18 & -1.80 \\
18.70 & 60.481 & 17.87 & -4.44 \\
37.40 & 126.032 & 37.95 & 1.46 \\
56.30 & 180.111 & 56.28 & -0.03 \\
65.80 & 213.169 & 67.87 & 3.15 \\
84.80 & 246.227 & 79.49 & -6.26 \\
93.80 & 293.962 & 96.24 & 2.60 \\
112.60 & 341.697 & 113.54 & 0.83 \\
132.00 & 384.331 & 130.55 & -1.10 \\
151.90 & 426.964 & 150.35 & -1.02 \\
172.20 & 489.369 & 186.35 & 8.22 \\
191.60 & 495.969 & 190.67 & -0.49 \\
210.50 & 503.527 & 195.71 & -7.03 \\
220.50 & 542.391 & 222.93 & 1.10 \\
232.00 & 720.000 & 231.81 & -0.08 \\
\hline
\end{tabular}




\subsection{Computational Results and Discussion}

As it is observed from inter-electrodes voltages measured from experiment, lower weights in grams resulted in higher voltage measurement, the gray-level $[\mathrm{K}]$, or pixel value, computed from the LBP which is proportional to deposited soot as well. Table 4.2 shows estimated soot mass computed using equation (3.3), and nonlinear polynomial equation (4.2). It also shows the percentage error based on the actual soot mass for the given tomographic image. Figure 4.5 shows the estimated vs actual soot masses . Figure 4.6 plots relative soot's estimation errors. Higher than normal percentage errors were observed at three data points $7 t h, 12 t h$, and $14 t h$ which can be attributed to the low voltage and weight measurement accuracy during the experiment. Estimated soot mass errors varies between $\pm 5 \%$ for the given DPF's tomographic images, as a result this range of errors reflects a close match between estimated and actual soot mass as shown in figure 4.5.

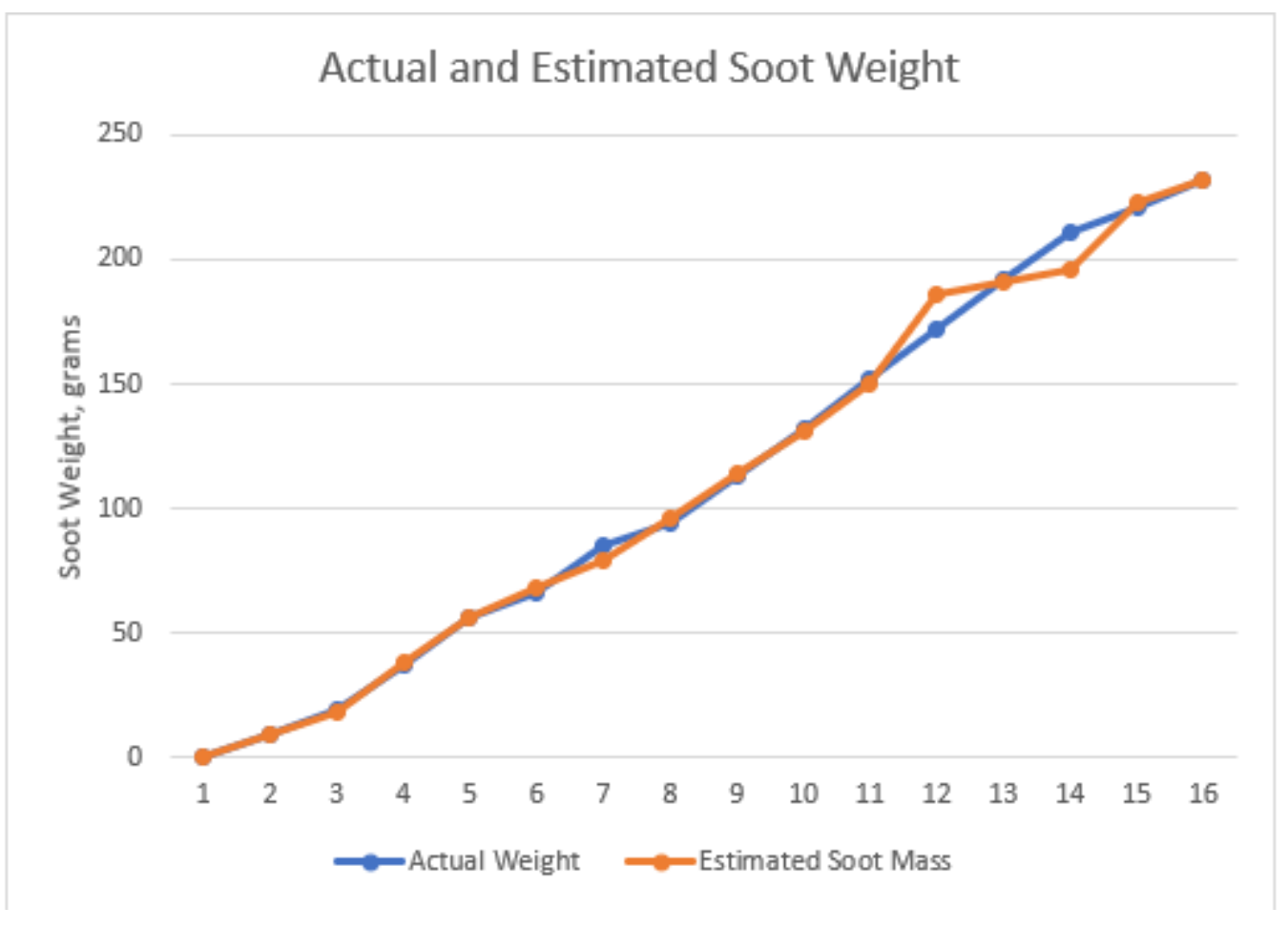

Figure 4.5.: Actual soot mass vs Estimated soot mass. 


\section{Estimation Error, \%}

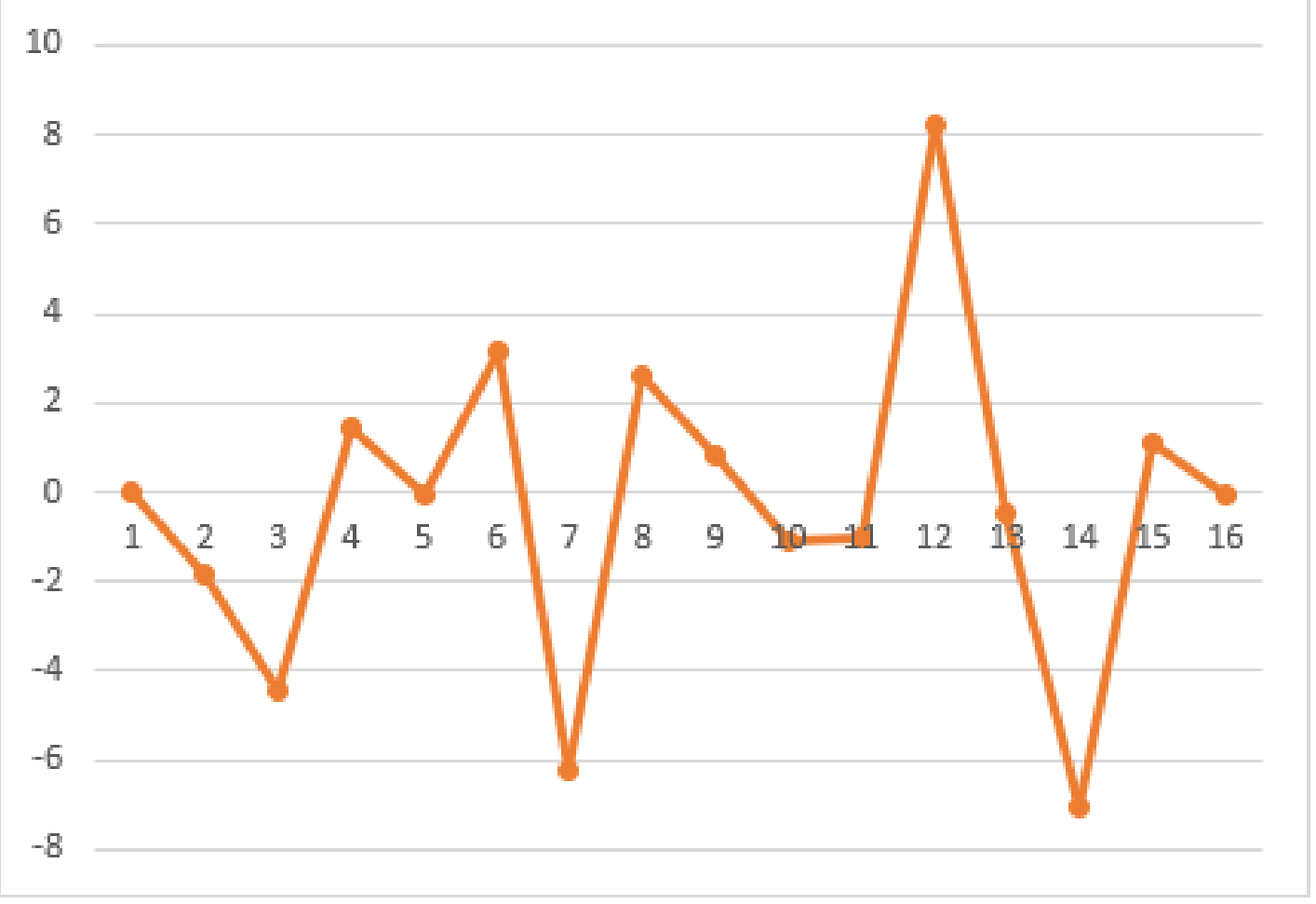

Figure 4.6.: Soot mass estimation accuracy 


\section{VALIDATION OF SOOT ESTIMATION USING FINITE ELEMENT ANALYSIS}

\subsection{ANSYS Electronic Maxwell 3D Model}

ANSYS Electronic Maxwell 3D is used to perform the validation analysis, since it has the capabilities of simulating electrical capacitance, with a wide range of material selection, by selecting the electrical physical properties, such as permittivity. A Maxwell capacitance matrix provides the relation between voltages on a set of conductors . For example, for a set of conductors, the following relation is valid:

$$
Q=C . V
$$

where $\mathrm{C}$ is the Maxwell capacitance matrix, $\mathrm{V}$ and $\mathrm{Q}$ are voltage and charge vectors respectively.

The mutual and auto capacitance are shown at the following four conductors set layout: [17]

$$
Q 1=C_{11} \cdot V_{1}+C_{12} \cdot\left(V_{1}-V_{2}\right)+C_{13} \cdot\left(V_{1}-V_{3}\right)+C_{14} \cdot\left(V_{1}-V_{4}\right)
$$

and 5.2 can be arranged as:

$$
\mathrm{Q} 1=\mathrm{V}_{1} \cdot\left(C_{11}+C_{12}+C_{13}+C_{14}\right)-V_{2} \cdot C_{12}-V_{3} \cdot C_{13}-V_{4} \cdot C_{14}
$$

the first row of the Maxwell capacitance vector $\mathrm{C}$ is

$$
\left[\begin{array}{llll}
C_{11}+C_{12}+C_{13}+C_{14} & -C_{12} & -C_{13} & -C_{14}
\end{array}\right]
$$




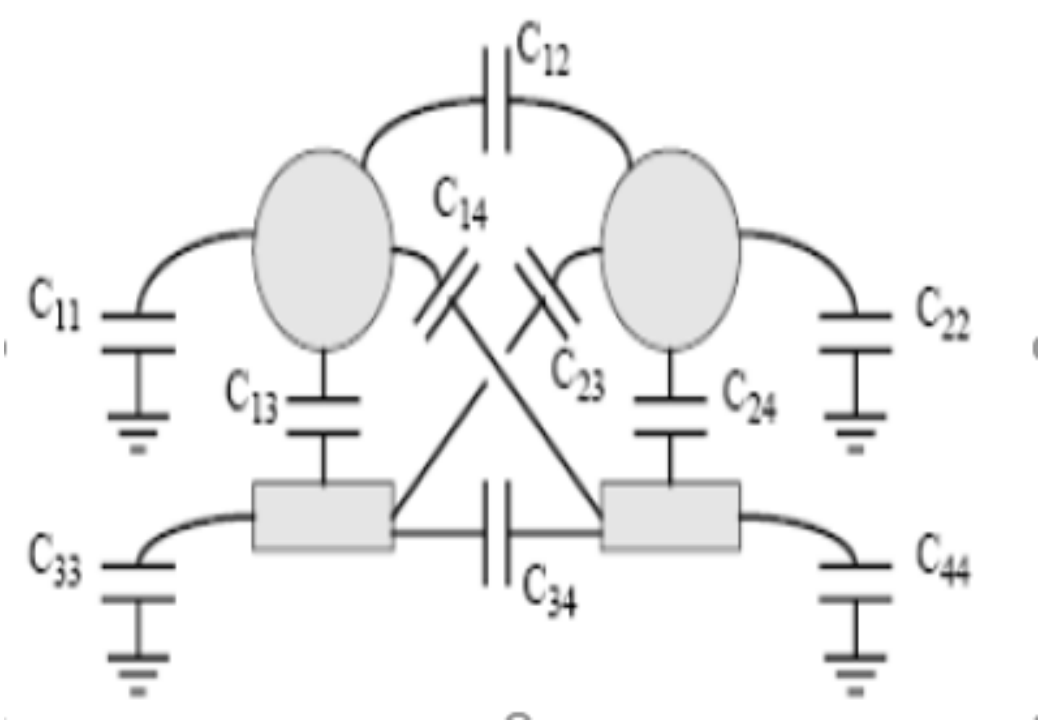

Figure 5.1.: Four Conductors' Mutual Capacitance [16]

By repeating the same derivation for Q 2, Q3, Q4, the full matrix has the form

$$
\left[\begin{array}{cccc}
C_{11}+C_{12}+ & -C_{12} & -C_{13} & -C_{14} \\
C_{13}+C_{14} & & & \\
-C_{21} & C_{21}+C_{22}+ & -C_{23} & -C_{24} \\
& C_{23}+C_{24} & & \\
-C_{31} & -C_{32} & C_{31}+C_{32} & -C_{34} \\
& & +C_{33}+C_{34} & \\
-C_{41} & -C_{42} & -C_{43} & C_{31}+C_{32}+ \\
& & & C_{33}+C_{34}
\end{array}\right]
$$




\subsection{Geometric Model}

A geometric model of the DPF assumed to be similar to the one used at the experimental modeling which was a cylindrical body of 6 inches diameter x 6 inches height, filter inner screen assumed to be a group of holes of 0.5 inch diameter for its design convenience, holes distribution on the DPF's cross-section matched pixels layout to be reconstructed as shown at the figure 5.3, four copper electrodes of thickness 0.2 inches fixed around the DPF circumference, as illustrated at figure 5.2 , however the DPF design is different ,but the simulation in Ansys Electronic assumed to be radial, and there is negligible affects.

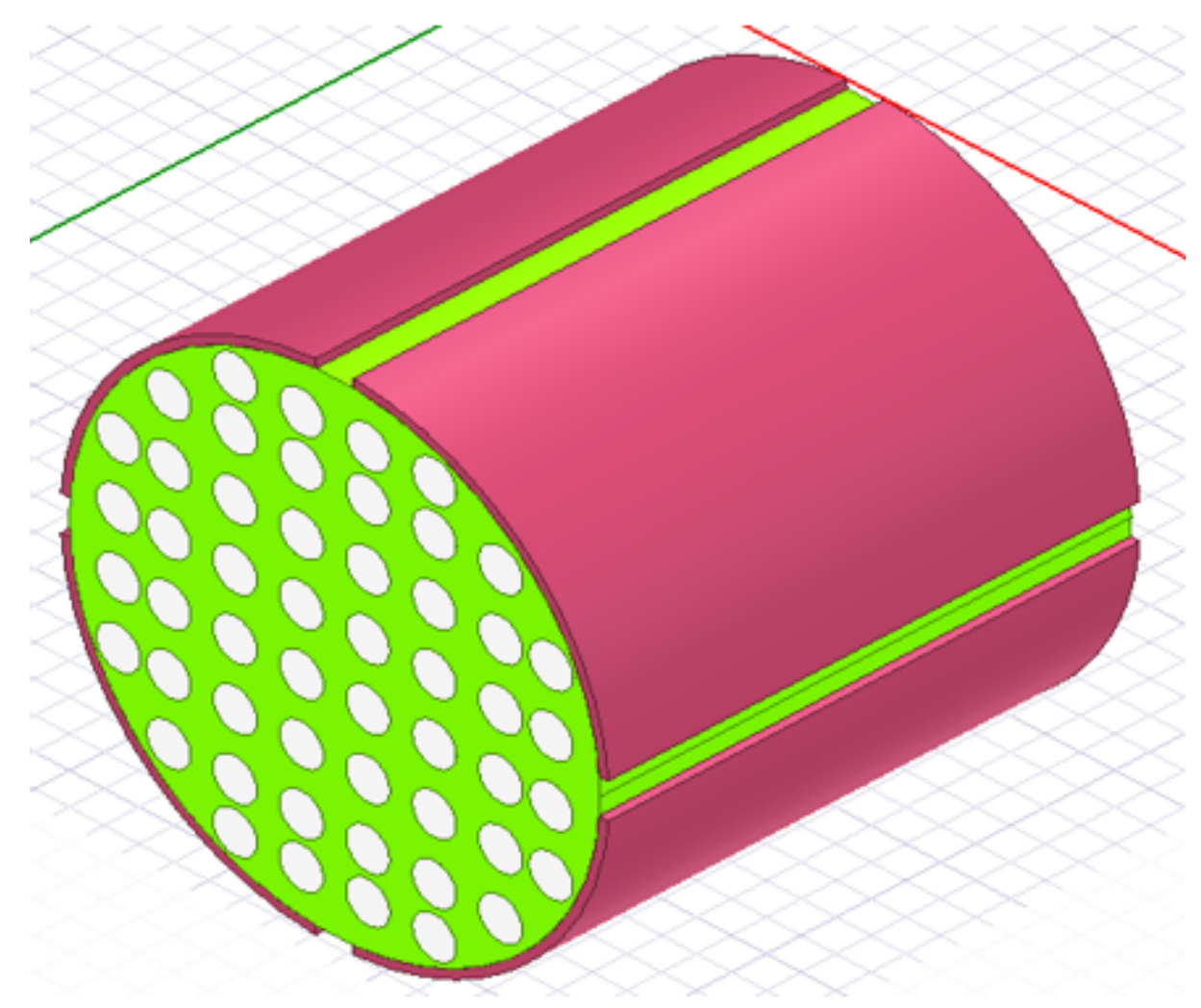

Figure 5.2.: Diesel Particulate Filter (DPF) 


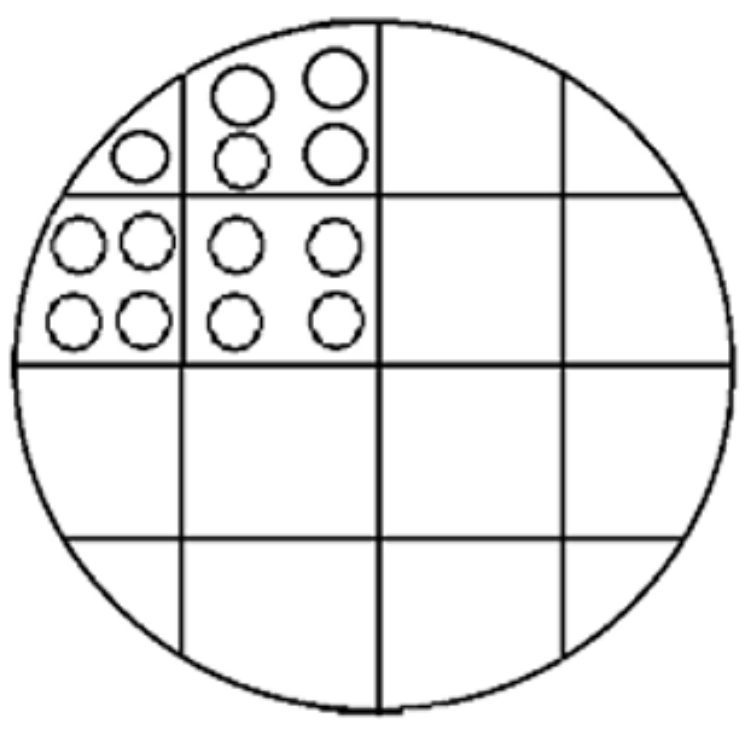

Figure 5.3.: Pixels and Holes Distribution

\subsection{Material Selection}

For the DPF body a permittivity of 4.0 assigned to match the original cordierite permittivity, for the four electrodes, copper material has been assigned, and it has a relative permittivity of 1 , a permittivity of 16.5 assigned to the soot which assumed to be a carbon black, and air of 1.0 permittivity assigned to empty holes

Table 5.1.: Material

\begin{tabular}{|c|c|c|c|}
\hline & DPF Sensor Component & Material & Relative Permittivity \\
\hline 1 & DPF body & Cordierite & 4 \\
\hline 2 & Electrodes & Copper & 1 \\
\hline 3 & Soot & Carbon Black & 16.5 \\
\hline 4 & Empty Holes & Air & 1 \\
\hline
\end{tabular}




\subsection{Electrodes Voltage and Solution Matrix}

In case of two conducting plates, a common form is a parallel-plate capacitor, which consists of two conductive plates insulated from each other, usually sandwiching a dielectric material, capacitance is approximately proportional to the surface area of the conductor plates and inversely proportional to the separation distance between the plates. However, the definition $\mathrm{C}=\mathrm{Q} / \mathrm{V}$ does not apply when there are more than two charged plates, or when the net charge on the two plates is non-zero. To handle this case, Maxwell introduced his coefficients of potential as it explained earlier in section 5.1

A charge of 5 volts applied to one of the four electrodes (source) while other three electrodes assigned (sink) and assumed to be ( 0 volts) one at a time, while the Maxwell Matrix of solution configured to be in Farads as shown in figure 5.4. A solution matrix set up determined at Ansys pre-determined parameter to select solution format as shown in table 5.2 and figure 5.5 respectively in capacitance (Farad)

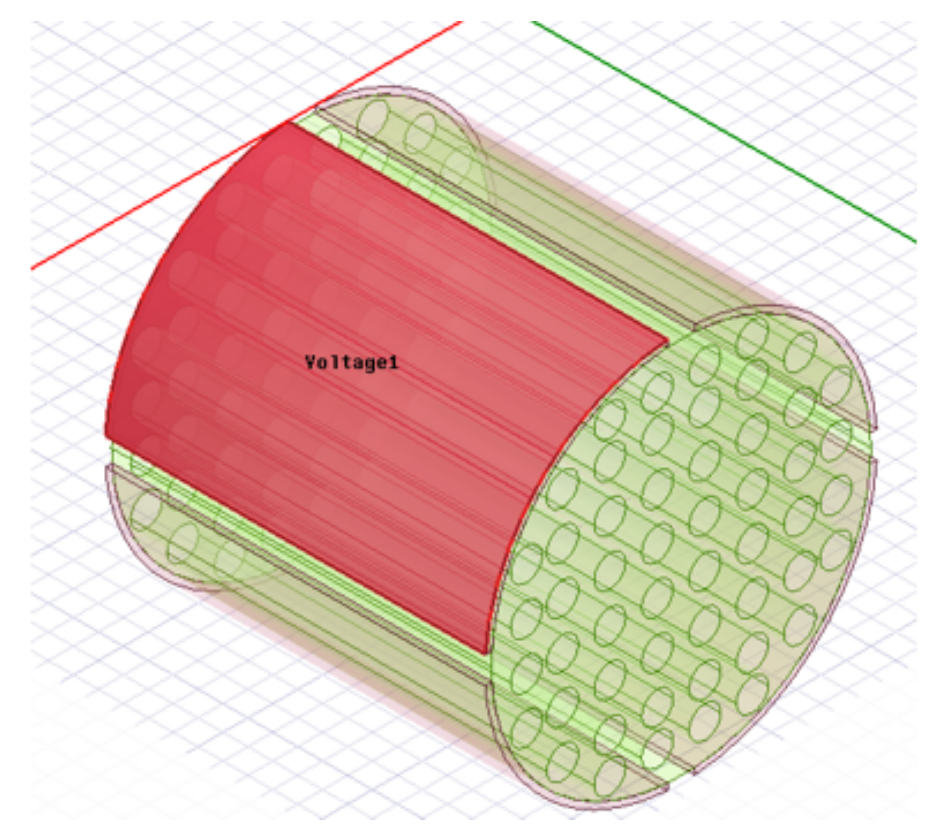

Figure 5.4.: Voltage of 5 Volts applied to Electrode 1 
Table 5.2.: Maxwell solution matrix set-up

\begin{tabular}{|c|c|c|c|c|}
\hline & Voltage 1 & Voltage 2 & Voltage 3 & Voltage 4 \\
\hline Voltage 1 & $\mathrm{x}$ & $\mathrm{x}$ & $\mathrm{x}$ & $\mathrm{x}$ \\
\hline Voltage 2 & $\mathrm{x}$ & $\mathrm{x}$ & $\mathrm{x}$ & $\mathrm{x}$ \\
\hline Voltage 3 & $\mathrm{x}$ & $\mathrm{x}$ & $\mathrm{x}$ & $\mathrm{x}$ \\
\hline Voltage 4 & $\mathrm{x}$ & $\mathrm{x}$ & $\mathrm{x}$ & $\mathrm{x}$ \\
\hline
\end{tabular}

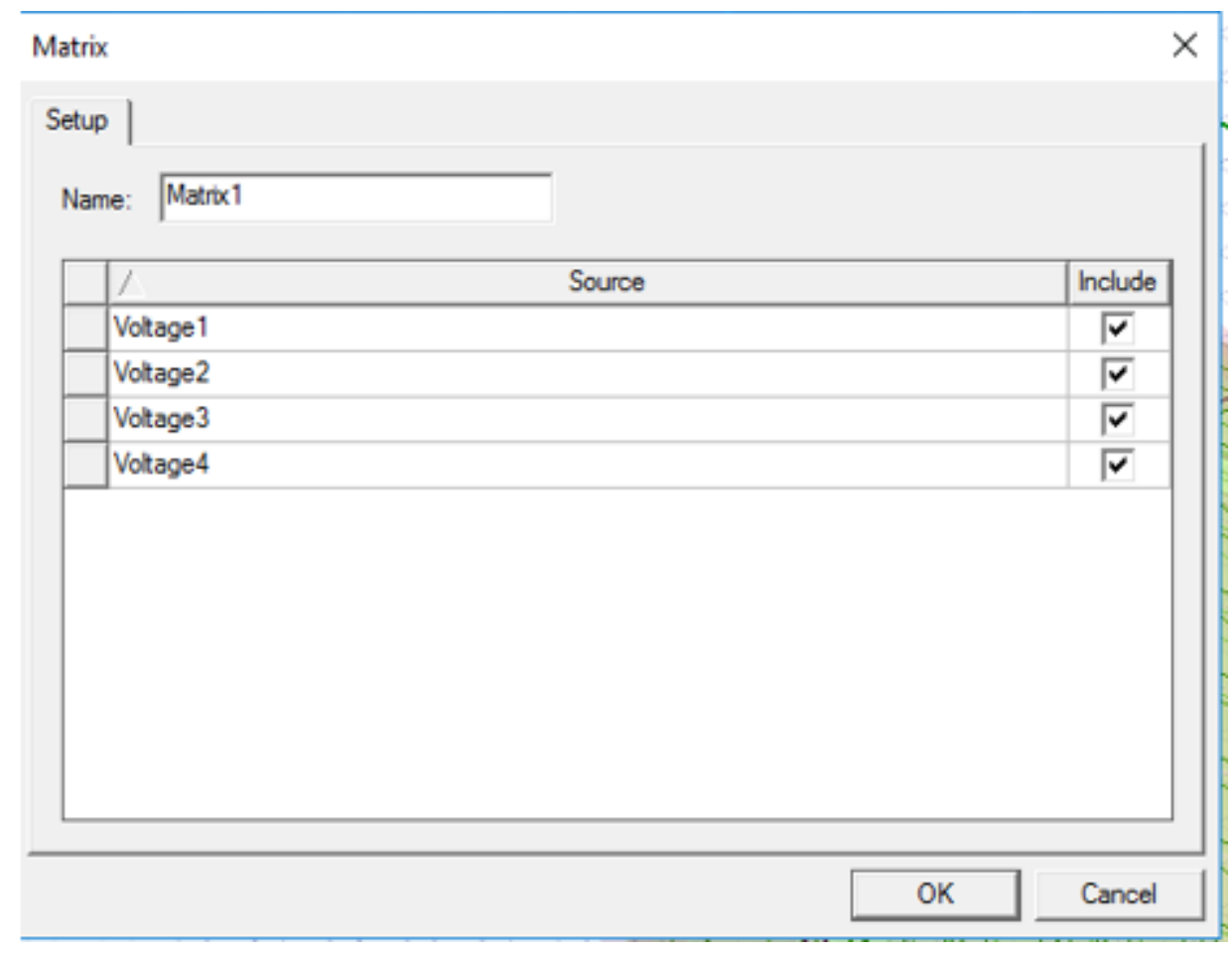

Figure 5.5.: Capacitance Solution Matrix in $\mathrm{pF}$

\subsection{Voltage Distribution Simulation}

Voltage is the difference in electric potential between two points, is explicitly related to the permittivity and capacitance in general as defined by equation :

$$
\mathrm{C}=\mathrm{Q} / \mathrm{V}
$$


while Capacitance is the ratio of the change in an electric charge in a system to the corresponding change in its electric potential, low permittivity, or low ability to hold a charge, high permittivity materials are good at holding charge, they are the preferred dielectric for capacitors. Voltage simulation shows in figure 5.6 energized electrode or sender, voltage signal declined as it move away countered by deposited soot.

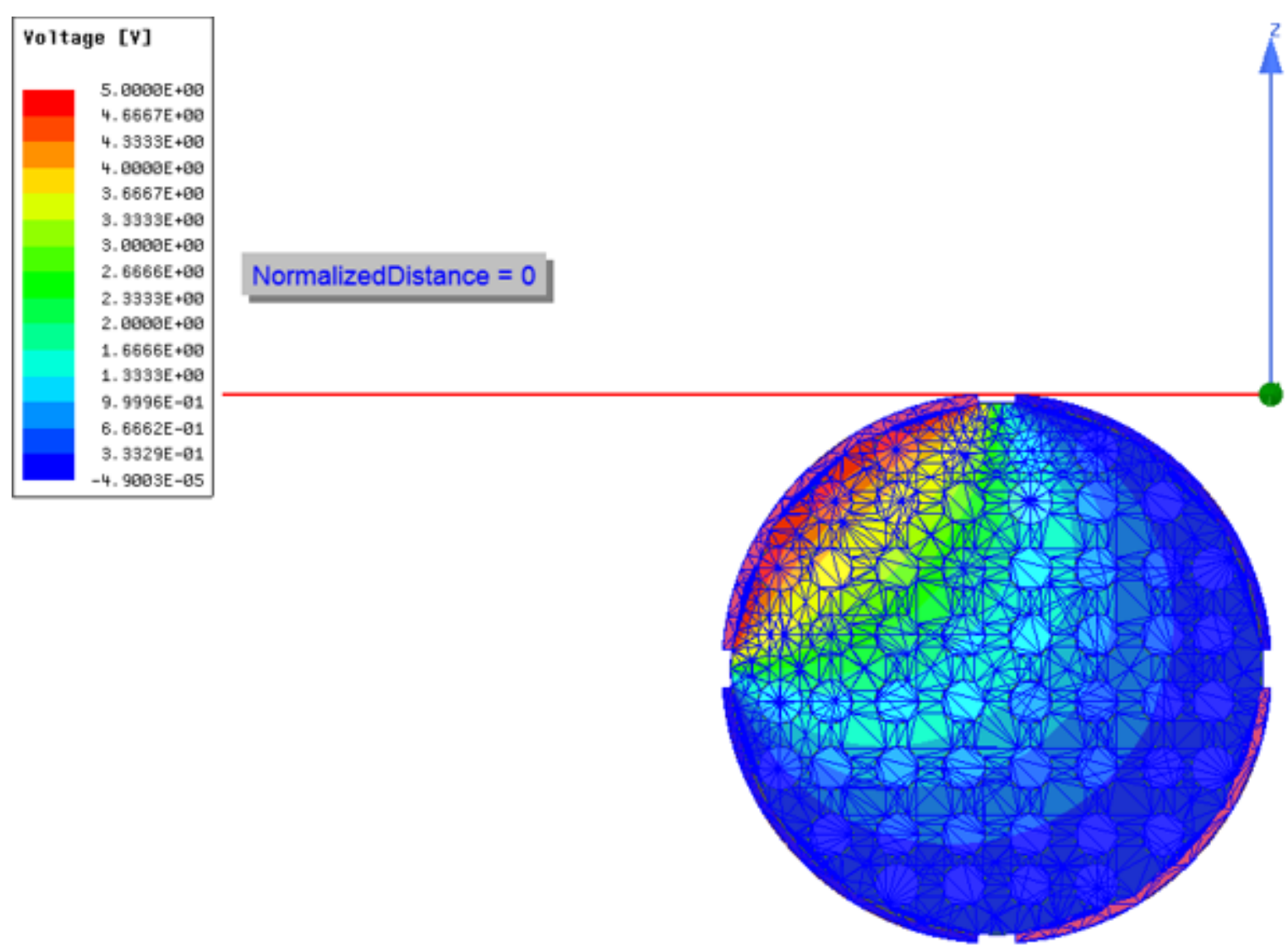

Figure 5.6.: Voltage Distribution

\subsection{Sensitivity Matrix}

Since the sensitivity matrix forms the foundation of the Linear Back projection (LBP) algorithm, it should be reconstructed first, instead of Direct Techniques method, an approach of pixel manually filling, initiated by first pixel and then transferred to the second, and so forth until reach the 16th pixel as shown in 
following table. In this reconstruction mode, only a single measurement data is used independently to implement sensitivity reconstruction matrix. While in first section study a Direct Techniques, method implemented to reconstruct the sensitivity matrix which essentially a normalization for the capacity data took from the inter-electrode measurement.

Table 5.3.: Sensitivity Matrix in $10^{-12}$ Farads (pF)

\begin{tabular}{|c|c|c|c|c|c|c|}
\hline Pixels/Electrodes & $1-2$ & $1-3$ & $1-4$ & $2-3$ & $2-4$ & $3-4$ \\
\hline 1 & 4.8057 & 0.80506 & 4.7921 & 4.7349 & 0.75515 & 4.7666 \\
2 & 4.9272 & 0.93281 & 5.7308 & 4.71 & 0.68944 & 4.6839 \\
3 & 4.6799 & 0.69847 & 5.5612 & 4.7206 & 0.88917 & 4.9204 \\
4 & 4.7357 & 0.75482 & 4.7886 & 4.7507 & 0.80433 & 4.8377 \\
5 & 5.7558 & 0.93443 & 4.912 & 4.6552 & 0.68784 & 4.7379 \\
6 & 4.8442 & 0.91986 & 4.8699 & 4.6532 & 0.84478 & 4.7209 \\
7 & 4.6692 & 0.84448 & 4.8599 & 4.6764 & 0.91994 & 4.9127 \\
8 & 4.6473 & 0.68803 & 4.9383 & 4.6243 & 0.92913 & 5.7154 \\
9 & 5.7398 & 0.68844 & 4.6378 & 4.9259 & 0.93282 & 4.7327 \\
10 & 4.8412 & 0.84467 & 4.6807 & 4.8318 & 0.91927 & 4.6792 \\
11 & 4.6089 & 0.91778 & 4.6356 & 4.7651 & 0.83963 & 4.8024 \\
12 & 4.5688 & 0.9272 & 4.5379 & 4.8032 & 0.68039 & 5.6469 \\
13 & 4.8036 & 0.75627 & 4.7169 & 4.8025 & 0.80369 & 4.7663 \\
14 & 4.9248 & 0.68909 & 4.6928 & 5.7536 & 0.93247 & 4.6807 \\
15 & 4.6549 & 0.93333 & 4.6919 & 5.7558 & 0.68721 & 4.9516 \\
16 & 4.7363 & 0.8047 & 4.7169 & 4.8034 & 0.7553 & 4.8306 \\
Empty DPF & 4.7466 & 0.77929 & 4.7275 & 4.8119 & 0.77768 & 4.8153 \\
Full DPF & 8.1929 & 1.8334 & 8.1873 & 8.3072 & 1.8309 & 8.3224 \\
\hline
\end{tabular}




\subsection{Capacitance Data Collection}

Two methods were adapted to obtain capacitance data from the inter-electrode excitation, the first was the random distribution and the other was circumferentially distributed soot inside DPF, where 3 holes filled initially from the center of DPF, and then incremented by 3 holes in spiral order until the DPF was fully filled, as we know the fundamental of ECT known as: different materials with different permittivities. If the concentration and the composition of the components are changed, the permittivity will change cross the DPF sensor, as a result this contrast in permittivity will cause a change of the capacitance measurements, for this reason, a randomly distributed soot inside the filter basically will test the real-life scenario, moreover, simulation data will give more opportunities to explore and analyze results and method. 
Table 5.4.: Random Filling Distribution in $10^{-12}$ Farads (pF)

\begin{tabular}{|c|c|c|c|c|c|c|}
\hline No. of holes filled/Electrodes & $1-2$ & $1-3$ & $1-4$ & $2-3$ & $2-4$ & $3-4$ \\
\hline 3 & 4.6337 & 0.75532 & 4.8746 & 4.605 & 0.80653 & 4.9252 \\
6 & 4.7519 & 0.77502 & 5.6992 & 4.6337 & 0.81404 & 4.8839 \\
9 & 4.8962 & 0.8525 & 5.8664 & 4.6646 & 0.75152 & 4.9086 \\
12 & 4.9844 & 0.96563 & 6.2696 & 4.5743 & 0.78424 & 4.8546 \\
15 & 5.002 & 0.93488 & 7.5725 & 4.5257 & 0.81393 & 4.9051 \\
18 & 5.1038 & 0.91989 & 8.1212 & 4.5741 & 0.88125 & 5.0862 \\
21 & 5.2064 & 1.0035 & 8.2019 & 4.5123 & 0.98415 & 5.3704 \\
24 & 5.1749 & 1.0413 & 8.4071 & 4.4809 & 1.1035 & 5.8656 \\
27 & 6.2277 & 1.1204 & 8.5123 & 4.4509 & 1.1089 & 5.835 \\
30 & 7.2335 & 1.1769 & 8.4064 & 4.4942 & 1.3098 & 5.9442 \\
33 & 7.2661 & 1.3763 & 8.3062 & 4.6056 & 1.3314 & 7.2451 \\
36 & 7.2107 & 1.5684 & 8.2823 & 4.7106 & 1.4247 & 7.3622 \\
39 & 7.1944 & 1.7966 & 8.155 & 4.9452 & 1.3844 & 7.9849 \\
42 & 7.957 & 1.6654 & 8.028 & 5.1722 & 1.5803 & 7.9456 \\
52 & 8.0791 & 1.7069 & 7.9668 & 5.671 & 1.7318 & 7.9229 \\
& 8.1929 & 1.8334 & 8.1873 & 8.3072 & 1.8309 & 8.3224 \\
\hline
\end{tabular}


Table 5.5.: Normalized Sensitivity Matrix

\begin{tabular}{|l|l|l|l|l|l|}
\hline 0.98 & 0.98 & 0.98 & 1.02 & 1.02 & 1.01 \\
0.95 & 0.85 & 0.71 & 1.03 & 1.08 & 1.04 \\
1.02 & 1.08 & 0.76 & 1.03 & 0.89 & 0.97 \\
1.00 & 1.02 & 0.98 & 1.02 & 0.97 & 0.99 \\
0.71 & 0.85 & 0.95 & 1.04 & 1.09 & 1.02 \\
0.97 & 0.87 & 0.96 & 1.05 & 0.94 & 1.03 \\
1.02 & 0.94 & 0.96 & 1.04 & 0.86 & 0.97 \\
1.03 & 1.09 & 0.94 & 0.00 & 0.86 & 0.74 \\
0.71 & 1.09 & 1.03 & 0.97 & 0.85 & 1.02 \\
0.97 & 0.94 & 1.01 & 0.99 & 0.87 & 1.04 \\
1.04 & 0.87 & 1.03 & 1.01 & 0.94 & 1.00 \\
1.05 & 0.86 & 1.05 & 1.00 & 1.09 & 0.76 \\
0.98 & 1.02 & 1.00 & 1.00 & 0.98 & 1.01 \\
0.95 & 1.09 & 1.01 & 0.73 & 0.85 & 1.04 \\
1.03 & 0.85 & 1.01 & 0.73 & 1.09 & 0.96 \\
1.00 & 0.98 & 1.00 & 1.00 & 1.02 & 1.00 \\
\hline
\end{tabular}




\subsection{Circumferential Distributed Soot}

Soot filled in DPF with one pattern, starting from the center and increasingly by three holes at a time spirally toward the DPF external circumference. This distribution will give more insights to explore dielectric distribution behavior and its contribution to the determining the mutual capacitance and eventually its effects on the gray-level value.

Table 5.6.: Circumferential Filling Distribution in $10^{-12}$ Farads (pF)

\begin{tabular}{|c|c|c|c|c|c|}
\hline No. of holes filled/Electrodes & $1-2$ & $1-3$ & $1-4$ & $2-3$ & $2-4$ \\
\hline 3 & 4.7083 & 0.89101 & 4.7439 & 4.7136 & 0.87617 \\
6 & 4.7974 & 0.97461 & 4.7242 & 4.7812 & 0.9763 \\
9 & 4.9498 & 1.0765 & 4.9358 & 4.7293 & 1.0347 \\
12 & 4.8856 & 1.1408 & 5.0349 & 4.74 & 1.1398 \\
15 & 4.8929 & 1.2666 & 4.9736 & 4.8953 & 1.1947 \\
18 & 5.2454 & 1.2224 & 4.9132 & 5.0942 & 1.3672 \\
21 & 5.7754 & 1.4039 & 5.136 & 5.0117 & 1.2818 \\
24 & 5.9007 & 1.5096 & 5.4308 & 4.9748 & 1.2499 \\
27 & 5.8096 & 1.3856 & 5.8374 & 4.9049 & 1.4571 \\
30 & 5.7559 & 1.5113 & 5.8226 & 5.0007 & 1.4741 \\
33 & 5.6825 & 1.723 & 5.4704 & 5.4099 & 1.3925 \\
36 & 5.9799 & 1.6304 & 5.6709 & 5.9733 & 1.5897 \\
39 & 7.713 & 1.5962 & 5.6622 & 6.1422 & 1.713 \\
42 & 8.2973 & 1.8194 & 6.492 & 6.0499 & 1.5411 \\
45 & 8.1707 & 1.6566 & 7.9332 & 5.9806 & 1.7671 \\
52 & 8.1929 & 1.8334 & 8.1873 & 8.3072 & 1.8309 \\
\hline
\end{tabular}




\section{ANSYS'S IMAGES AND COMPUTATIONAL RESULTS}

\subsection{Soot Estimation Method using ANSYS Images}

Based on chapter 5 material, ECT images were generated from ANSYS modeling using LBP.The following images represent randomly filled holes of the DPF. As it can be observed from figure 6.1.a which has 36 filled holes, 6.1.b has 18 filled holes, 6.1.c has 12 filled holes, and 6.1.d has 3 filled holes. Gray-level varied from 36 filled holes down to 3 filled holes.

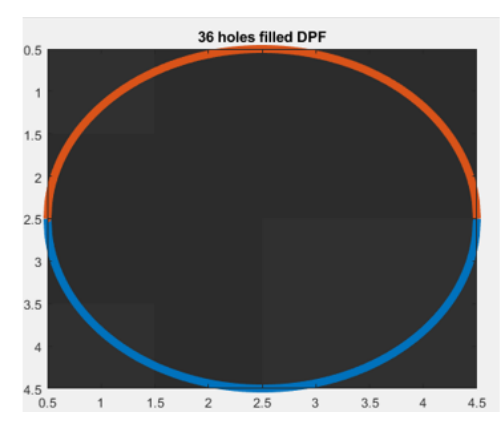

(a) 36 filled holes.

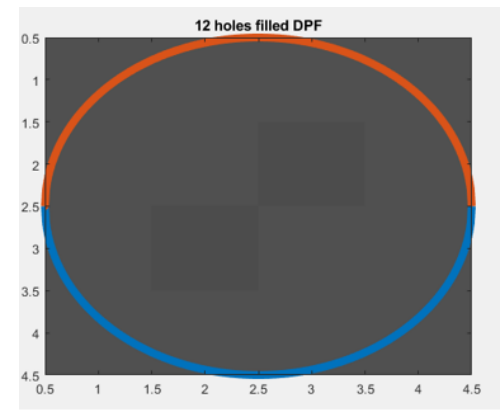

(c) 12 filled holes.

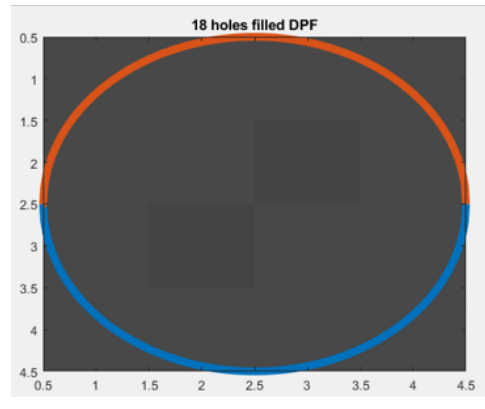

(b) 18 filled holes.

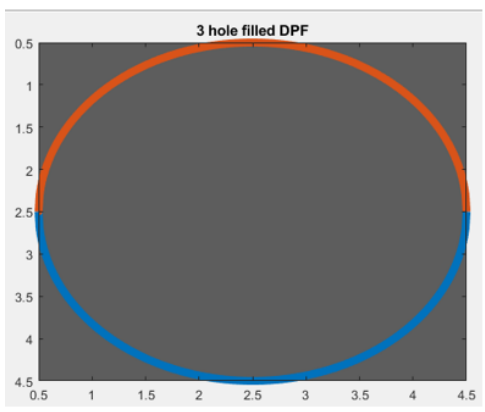

(d) 3 filled holes.

Figure 6.1.: Randomly Distributed and filled holes. 


\subsection{Images (Gray-Level)- Circumferential Distributed Soot}

From the simulation results a numerical sum of vector $[\mathrm{K}]$ obtained as shown in LBP equation:

$$
[K]=[S]^{T} \cdot[C]
$$

While filled soot amount inside the DPF (Maxwell model) calculated using carbon black physical, and geometrical properties. Similar calculation method explained at section (3.1), a numerical sum of the gray-level $[\mathrm{K}]$ vector assumed to be related to the deposited soot. The numerical sum of $[\mathrm{K}]$ represents the gray-level value used to estimate the filled soot, for both Random and circumferential soot filling arrangement, a non-linear polynomial equation derived using excel curve fitting tools, polynomial equation (4.1)

$$
y=a_{1} x^{6}+a_{2} x^{5}+a_{3} x^{4}+a_{4} x^{3}+a_{5} x^{2}+a_{6} x+a
$$

Using curve fitting tools in MS Excel $\mathrm{a}_{1}, a_{2}, a_{3}, a_{4}, a_{5}$, and $a_{6}$ can be located respectively as below:

1- Random Distribution

$y=(-5 E-07) x^{5}+(6 E-05) x^{4}-0.0028 x^{3}+0.0502 x^{2}-0.5295 x+17.406$

where $\mathrm{y}$ estimated number of holes filled, and $\mathrm{x}$ is gray level value. Polynomial equation coefficients $\mathrm{a}_{1}, a_{2}, a_{3}, a_{4}, a_{5}$, and $a_{6}$ are :

$$
\begin{aligned}
& \mathrm{a}_{1}=1.52118 E-05 \quad, a_{2}=-0.000550069 \quad, a_{3}=0.003228188 \\
& \mathrm{a}_{4}=0.076203506, \quad a_{5}=-1.078575735, \quad a_{6}=1.616596238
\end{aligned}
$$

2- Circumferential Distribution:

$y=-0.0002 x^{6}+0.0109 x^{5}-0.2395 x^{4}+2.5302 x^{3}-12.891 x^{2}+23.73^{x}+51.998$

Polynomial equation coefficients $\mathrm{a}_{1}, a_{2}, a_{3},, a_{4}, a_{5}$, and $a_{6}$ are :

$$
\begin{aligned}
& \mathrm{a}_{1}=-0.000191585, \quad a_{2}=0.010889287, \quad a_{3}=-0.239540012 \\
& \mathrm{a}_{4}=2.530212898, \quad a_{5}=-12.89055524, \quad a_{6}=23.72970661 \\
& \mathrm{a}=0
\end{aligned}
$$




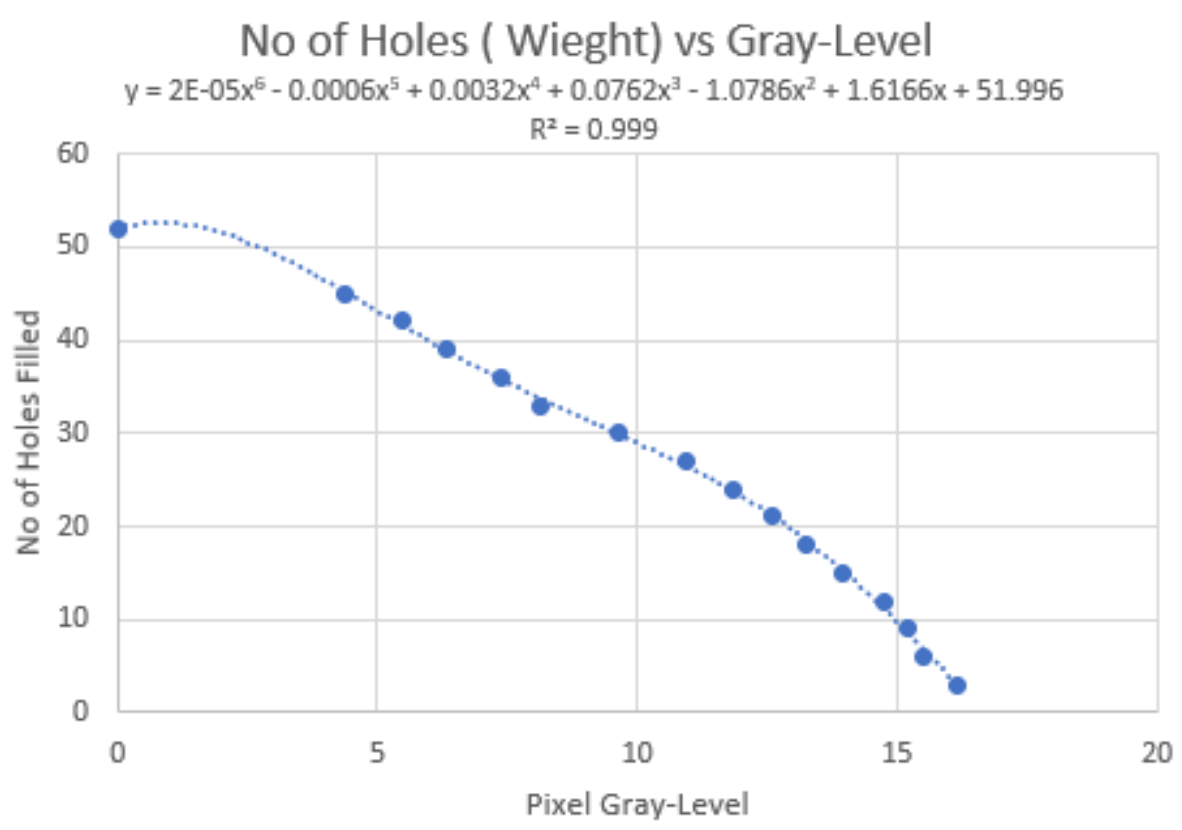

Figure 6.2.: Randomly Distributed Soot

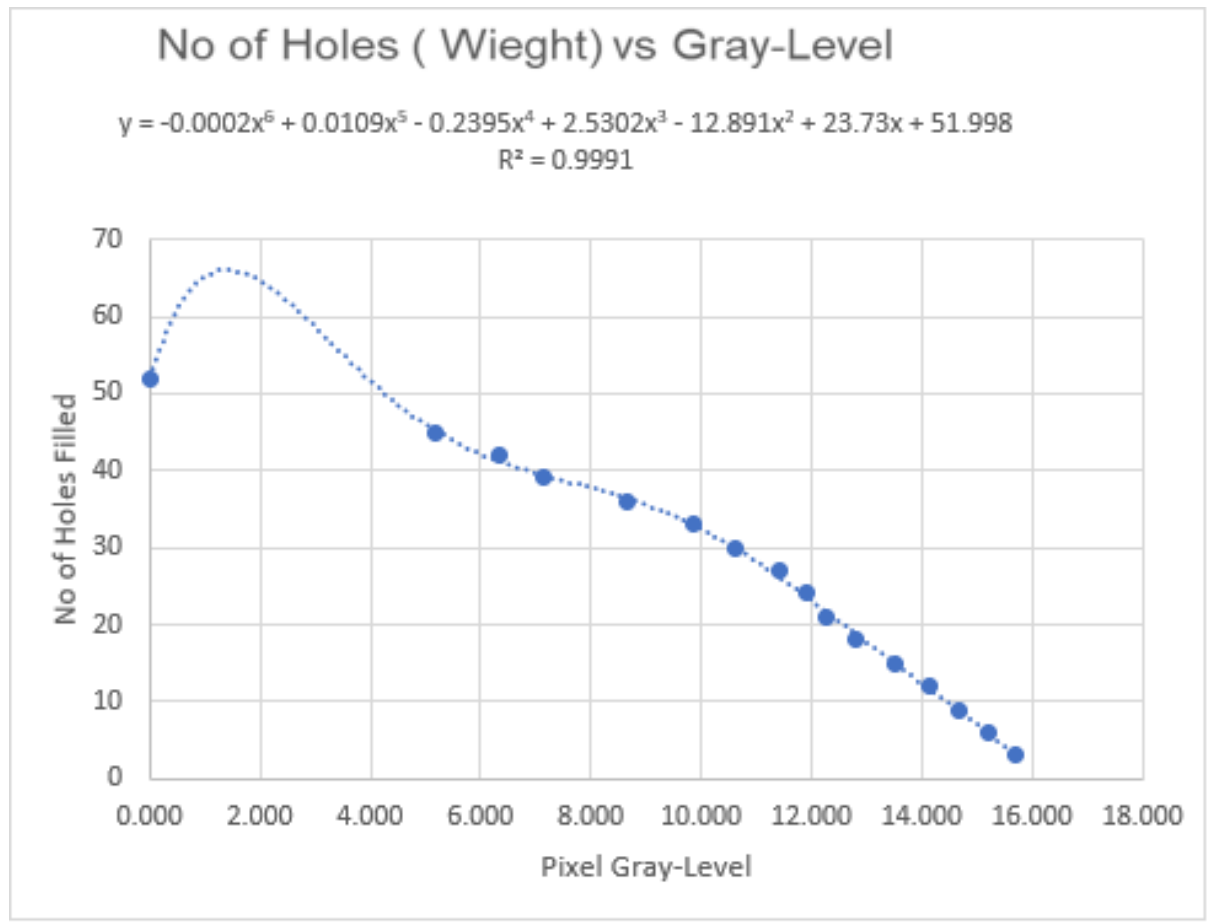

Figure 6.3.: Circumferential Distributed Soot 
Table 6.1.: Nos. of filled holes vs Gray-Level Random Distribution

\begin{tabular}{|c|c|c|c|c|}
\hline & Gray-Level Value & $\begin{array}{r}\text { Actual Weight } \\
\text { No of Filled Holes }\end{array}$ & $\begin{array}{c}\text { Estimated Weight } \\
\text { (No of holes) }\end{array}$ & Error \% \\
\hline 1 & 16.15794723 & 3 & 2.907553055 & -3.081564835 \\
2 & 15.5001599 & 6 & 6.847677051 & 14.12795085 \\
3 & 15.21758948 & 9 & 8.498537666 & -5.571803715 \\
4 & 14.74457232 & 12 & 11.16428706 & -6.964274527 \\
5 & 13.94898682 & 15 & 15.29055728 & 1.93704853 \\
6 & 13.23313331 & 18 & 18.56450207 & 3.136122635 \\
7 & 12.58396253 & 21 & 21.17123573 & 0.815408251 \\
8 & 11.8198292 & 24 & 23.84135302 & -0.661029066 \\
9 & 10.94508015 & 27 & 26.47594141 & -1.94095774 \\
10 & 9.650045982 & 30 & 29.88222004 & -0.392599871 \\
11 & 8.154963213 & 33 & 33.69012893 & 2.091299794 \\
12 & 7.36324128 & 36 & 35.8512668 & -0.413147777 \\
13 & 6.310931613 & 39 & 38.96986668 & -0.077264935 \\
14 & 5.473303797 & 42 & 41.63196323 & -0.876278023 \\
15 & 4.376593173 & 45 & 45.20785969 & 0.461910421 \\
16 & 0 & 52 & 51.996 & -0.007692308 \\
\hline
\end{tabular}


Table 6.2.: Circumferential Distribution Estimated Weight

\begin{tabular}{|c|c|c|c|c|}
\hline & Gray-Level Value & Actual Weight & $\begin{array}{c}\text { No of Filled } \\
\text { Holes }\end{array}$ & Error \% \\
\hline 1 & 15.691 & 3 & 3.06 & 1.908 \\
2 & 15.187 & 6 & 6.07 & 1.203 \\
3 & 14.666 & 9 & 8.89 & -1.249 \\
4 & 14.146 & 12 & 11.61 & -3.250 \\
5 & 13.511 & 15 & 14.97 & -0.224 \\
6 & 12.814 & 18 & 18.74 & 4.132 \\
7 & 12.271 & 21 & 21.70 & 3.336 \\
8 & 11.926 & 24 & 23.55 & -1.878 \\
9 & 11.408 & 27 & 26.22 & -2.887 \\
10 & 10.607 & 30 & 29.97 & -0.092 \\
11 & 9.859 & 33 & 32.90 & -0.296 \\
12 & 8.632 & 36 & 36.42 & 1.168 \\
13 & 7.130 & 39 & 39.41 & 1.056 \\
14 & 6.318 & 42 & 41.24 & -1.812 \\
15 & 5.159 & 45 & 45.25 & 0.559 \\
16 & 0.000 & 52 & 52.00 & -0.004 \\
\hline
\end{tabular}


Table 6.3.: Random vs Circumferential Distribution (Errors)

\begin{tabular}{|c|c|c|c|}
\hline $\begin{array}{c}\text { Estimated Weight } \\
\text { Circular }\end{array}$ & $\begin{array}{c}\text { Estimated weight } \\
\text { Random }\end{array}$ & Circular-Error \% & Random - Error \% \\
\hline 3.06 & 2.91 & 1.91 & -3.08 \\
6.07 & 6.85 & 1.20 & 14.13 \\
8.89 & 8.50 & -1.25 & -5.57 \\
11.61 & 11.16 & -3.25 & -6.96 \\
14.97 & 15.29 & -0.22 & 1.94 \\
18.74 & 18.56 & 4.13 & 3.14 \\
21.70 & 21.17 & 3.34 & 0.82 \\
23.55 & 23.84 & -1.88 & -0.66 \\
26.22 & 26.48 & -2.89 & -1.94 \\
29.97 & 29.88 & -0.09 & -0.39 \\
32.90 & 33.69 & -0.30 & 2.09 \\
36.42 & 35.85 & 1.17 & -0.41 \\
39.41 & 38.97 & 1.06 & -0.08 \\
41.24 & 41.63 & -1.81 & -0.88 \\
45.25 & 45.21 & 0.56 & 0.46 \\
52.00 & 52.00 & 0.00 & -0.01 \\
\hline & & & \\
\hline
\end{tabular}

\subsection{Ansys Validation and Results and Discussion}

Capacitance measurements obtained from inter-electrode data, forms a direct relationship between capacitance and material deposited inside the DPF, this form exhibits proportional relationship, in-line with the assumption of more soot deposited results in more capacitance,although, The capacitance of a set of charged parallel plates is increased by the insertion of a dielectric material. The capacitance is inversely proportional to the electric field between the plates, and the presence of the 
dielectric reduces the effective electric field. on other hand capacitance is following direct proportional of soot mass contribution at the time capacitances were measured.

In Validation process two pattern of soot mass deposition implemented, random soot distribution, and circumferential soot distribution,in order to explore and observe the behavior of simulation results, from the charts there were slight difference, the errors in circumferential tends to be less than $\pm 5 \%$, while random distribution's exceeded errors acceptable range in three points, these spikes attributed to some limitation in Ansys electronic desktop where no feature to electrically ground electrodes, besides, the difficulty of transforming DPF circular shape into square pixel domain.

Results as illustrated in figures circumferential distribution showed the best results, however in real time estimation method should apply for all situation.

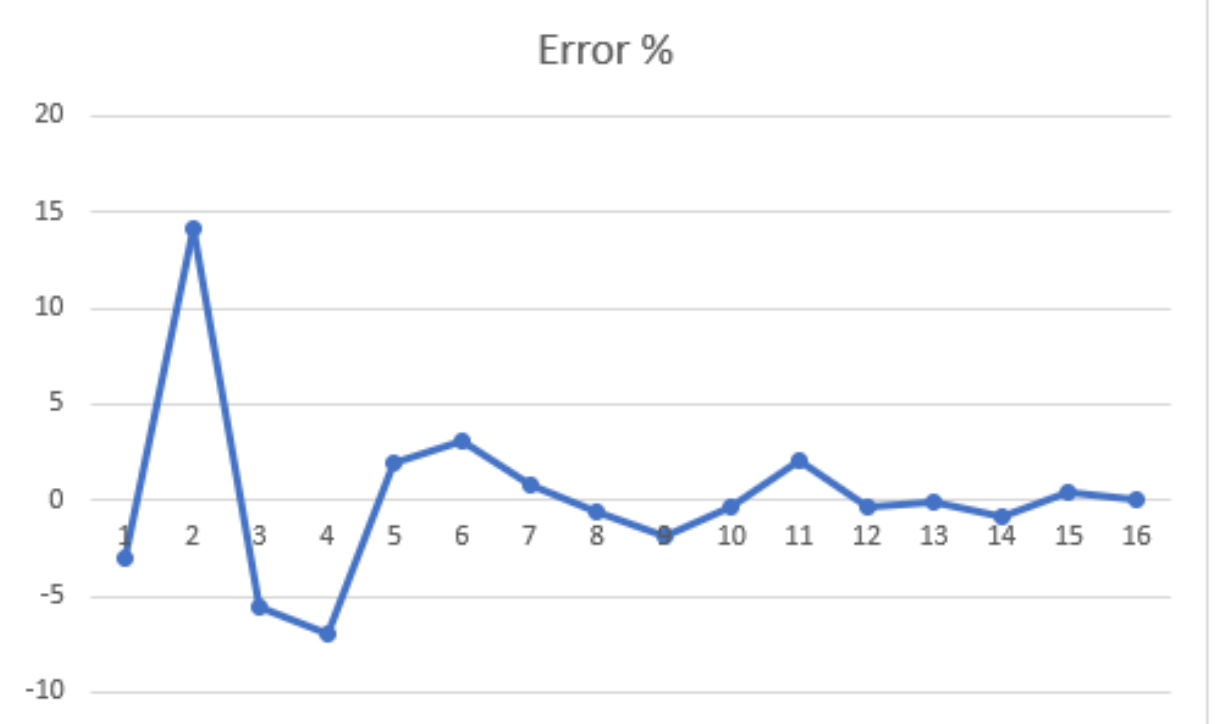

Figure 6.4.: Random Distribution Error\%

The estimation errors for the case with DPF holes filled randomly are plotted in figure 6.4.; a maximum error of $14 \%$ is observed. 


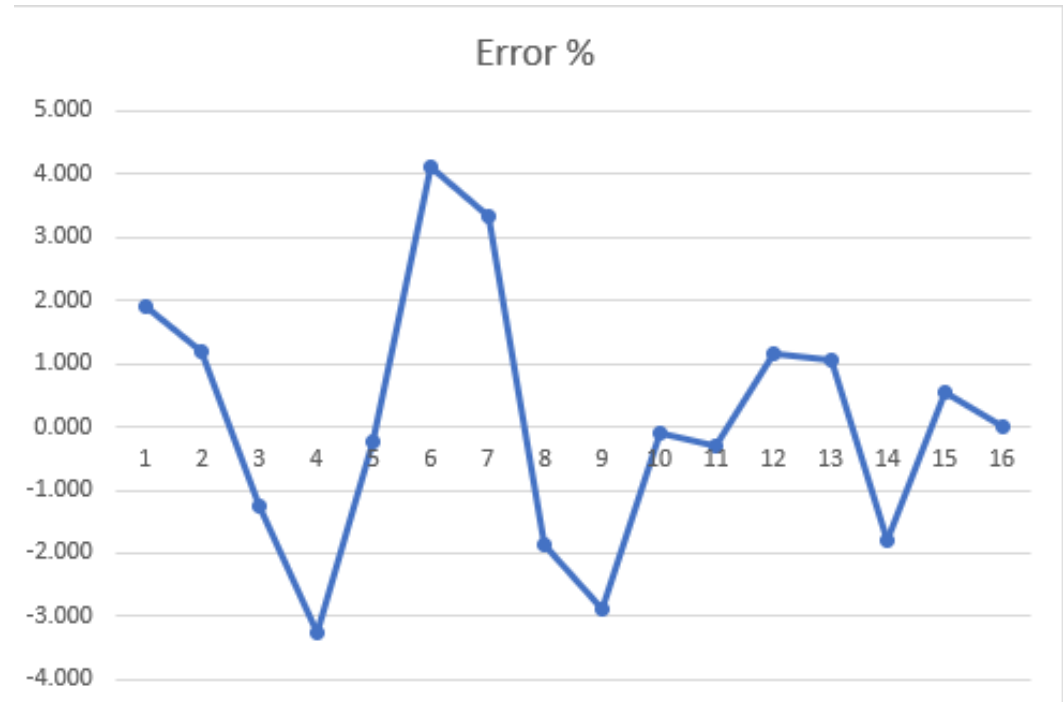

Figure 6.5.: Circumferential Distribution -Actual Nos of holes filled vs Estimated

The estimation errors for the case with DPF holes filled circumferentially as shown in figure 6.5; estimation errors were in the acceptable range of maximum $4 \%$.

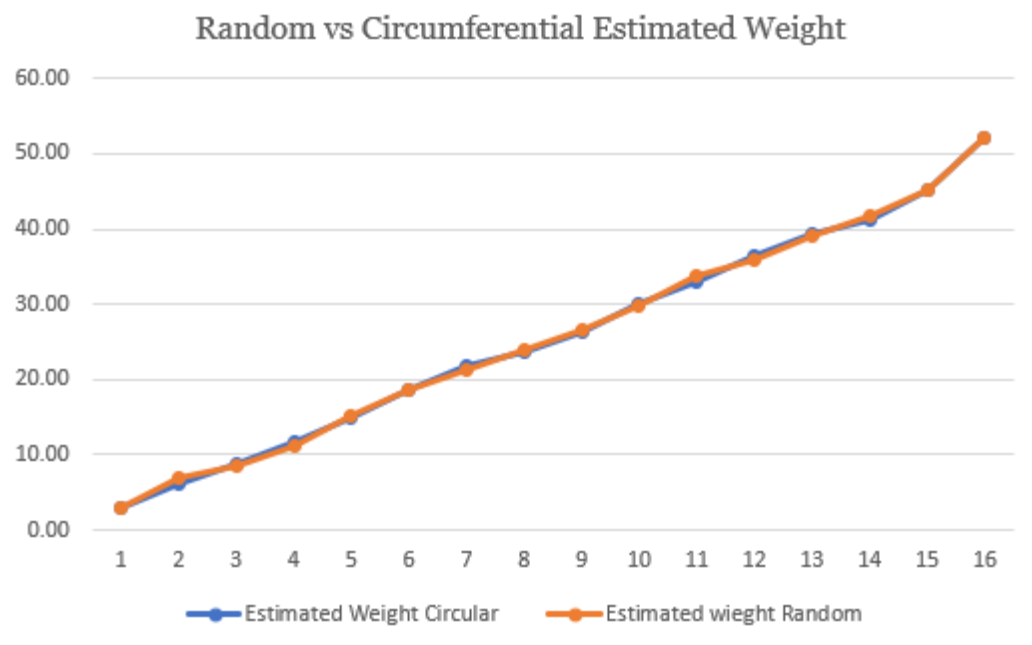

Figure 6.6.: Random vs Circumferential Distribution

Soot weight estimation patterns were plotted as shown in figure 6.6. A close match between random and circumferential distribution, based on the number of filled holes was observed. 


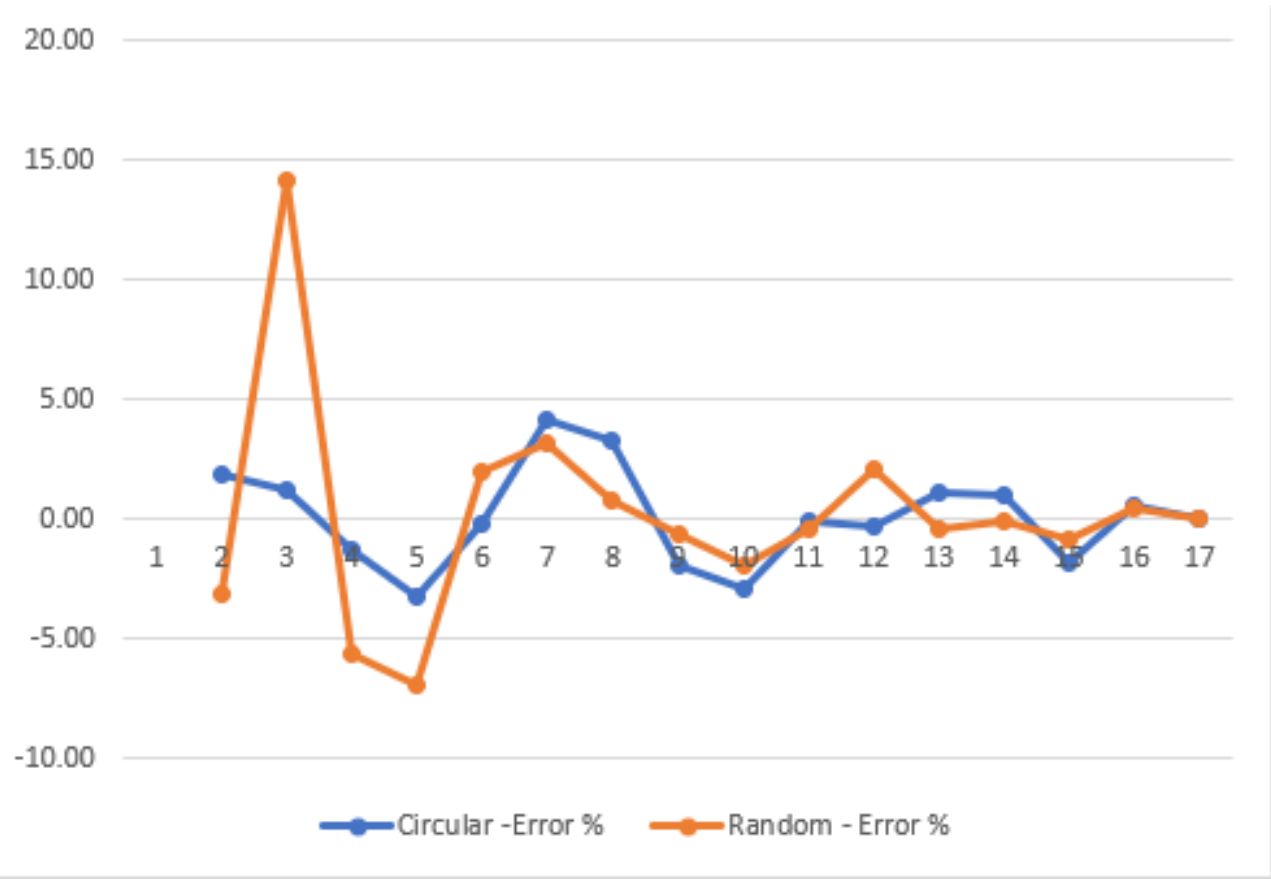

Figure 6.7.: Random vs Circumferential Distribution Errors

Figure 6.7 shows the soot estimation errors for soot distributed randomly and circumferentially. 


\section{CONCLUSION AND FUTURE WORK}

\subsection{Conclusion}

The aim of the presented work was to estimate soot mass from generated ECT image's data. Sensitivity matrix for an ECT image forms a basis set from which image pixel data can be obtained. In this research, an approach is presented to estimate the soot mass in a Diesel Particulate Filter from an ECT image utilizing its permittivity (capacitance) data, and then making use of pixel's gray-level data for estimation process .MATLAB software was used as a tool for processing the digital image data, and generating numerical values, for both experimental and validation portions. The proposed approach was evaluated for its accuracy against actual soot mass and its corresponding tomographic images data. The results obtained by combining the pixel value with soot load physical properties (weight) and permittivity parameters (capacitance) through nonlinear relationship showed reasonable accuracy in estimating the actual soot mass. Moreover it has been observed from the experimental data and validation results, soot estimation computation and analysis showed that voltage is proportional to deposited soot weight, while capacitance data used in simulation displayed inversely proportional relationship between number of holes filled with soot. This results coincide with the basic definition of relationship between charge, voltage, and capacitance, and proves that experimental and validation results are on the right track, however there are small estimation errors in the results but they are controllable by enhancing sensor electrode and procedures in experimental data collection. 


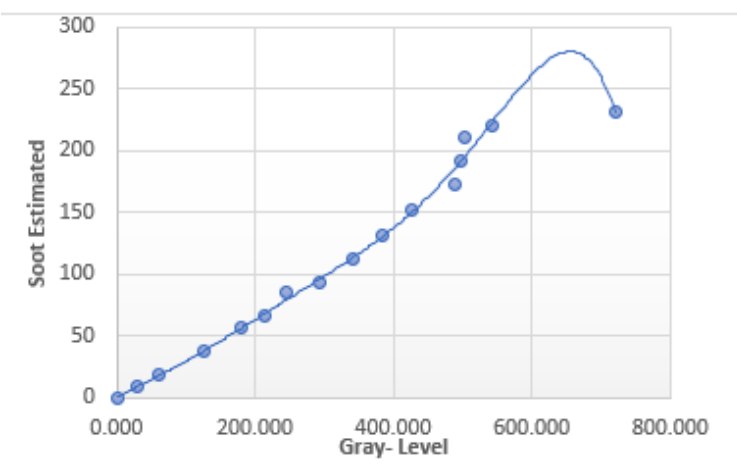

(a) Voltage vs Estimated Soot.

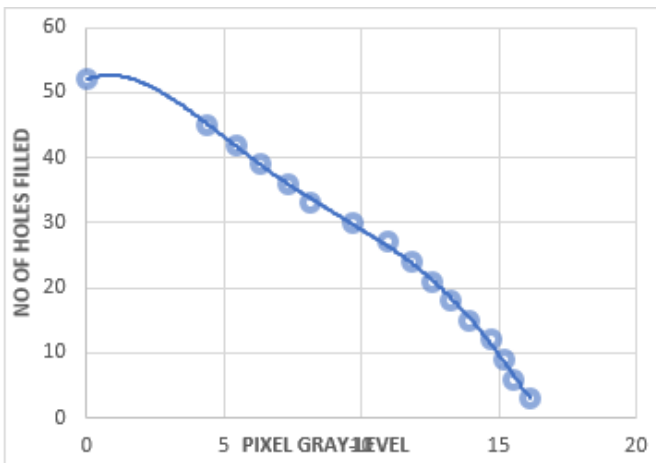

(b) Capacitance vs Estimated Soot.

Figure 7.1.: Voltage fill-in data vs Gray-Level (Experimental), and Capacitance fill-in data vs Gray-Level (validation).

\section{2 $\quad$ Future Work}

Controlling the soot mass deposition / emission level in the diesel engines exhaust system is a crucial process for manufacturers and environmental regulators. Several studies have been conducted to figure out this problem using experimental, analytical, and numerical approaches, however there are some challenges still need further investigations. Based on the conclusions drawn from the study performed herein, the following concerns can be basis for future work to advance improvement in this area.

1- The ANSYS software used in this study to create a finite element model of the diesel particulate filter (DPF) does not include a function for the electrical ground system. This resulted in spikes on capacitance reading which impacted the accuracy and linearity of the field distribution. Technically, the negligence of the electrical ground system leads to residual accumulation and flow of the electrical field which eventually impacts sensor's electrodes mutual capacitance .

2- The sensitivity matrix used in this study as tools / techniques to quantify the soot mass accumulation can be improved by weighing more geometric models capable of transforming circular cross-section of the filter outer shell into square pixel grid, as it 
assumed a full size of the outer pixels during the data transformation into a sensitivity matrix. This assumption slightly affects the accuracy of the sensitivity's matrix .

3- Two approaches implemented to generate sensitivity matrix , Direct technique and Manual deposition, other approaches could be tried to improve the quality of the images generated as well. 
REFERENCES 


\section{REFERENCES}

[1] R. Huq and S. Anwar, "Real-time soot measurement in a diesel particulate filter," US Patent 9,151,20, 2015.

[2] Du, Yanting, H. Guangdi, X. Shun, Z. Ke, L. Hongxing, and G. Feng, "Estimation of the diesel particulate filter soot load based on an equivalent circuit model". Energies, vol. 11, no. 2, 2018.

[3] G. Ramón. "after-treatment systems DPF (Diesel Particulate Filter)". [Online]. Available: http://www.drawfolio.com/en/portfolios/ramongarciagonzalez/picture/50223picture-navigation

[4] W. Wade, "Diesel particulate trap regeneration techniques". SAE Technical Paper 810118, 1981.

[5] P. Chen and J. Wang, "Control-oriented model for integrated diesel engine and aftertreatment systems thermal management". Control Eng. Pract., vol. 22, pp.81-93, 2014.

[6] E. Alhosani, Electrical capacitance tomography for real-time monitoring of process pipelines . A thesis submitted for the degree of Doctor of Philosophy,University of Bath Department of Electronic Electrical Engineering, 2016.

[7] M. Zhang, Permittivity and Conductivity Imaging in Electrical Capacitance Tomography . The thesis submitted for the degree of Doctor of Philosophy , The Department of Electronic and Electrical Engineering University of Bath g, 2015.

[8] Q. Marashdeh, "Advances in Electrical Capacitance Tomography". The Ohio State University: MS Thesis, 2006.

[9] A. Jaworski and T. Dyakowski, "Application of electrical capacitance tomography for measurement of gas-solid flow characteristics in a pneumatic conveying system". Measurement Science and Technology, vol. 12, pp 1109, 2001.

[10] T. Masturah, R. M, Z. Zulkarnay, R. A, and N. M. Ayob, "Design of Flexible Electrical Capacitance Tomography Sensor”. Jurnal Teknologi, vol. 77, no. 28, 2015.

[11] Soleimani, Manuchehr, and L. William, RB, "Nonlinear image reconstruction for electrical capacitance tomography using experimental data". Reading Massachusetts: Measurement Science and Technology , vol. 16, no. 10, pp 1987-1996, 2005.

[12] R. White, "Using electrical capacitance tomography to monitor gas voids in a packed bed of solids". Meas. Sci.Technol, vol. 13,pp. 1842-1847, 2002. 
[13] A. Brahma, "Modeling and Observability Analysis of DPF Regeneration". Ann Arbor, USA: ASME 2008 Dynamic Systems and Control Conference, 2008.

[14] Y. W, Q and P. Lihui, "Image reconstruction algorithms for electrical capacitance tomography". Measurement Science Technology, 2003.

[15] M. Huang, A. Plaskowski, C. Xie, and M. Beck, "Capacitance-based tomographic flow imaging system". Electronics letters, vol. 24, no. 7, pp. 418-419, 1988.

[16] A. Kowalska, B. Robert, W. Radosław, R. Andrzej, and D. Sankowski, "Towards high precision electrical capacitance tomography multi-layer sensor structure using 3D modelling and 3D printing method". International Interdisciplinary PhD Workshop (IIPhDW), pp. 238-243. IEEE, 2018.

[17] W. Paper, The Maxwell Capacitance Matrix. White Paper WP110301, 2011. 